\title{
Striatum and language processing: Where do we stand?
}

\author{
Charlotte Jacquemot ${ }^{\text {a, b, c }}$, Anne-Catherine Bachoud-Lévi ${ }^{\text {a, bcd, * }}$ \\ a Département d'Etudes Co gnitives, École no rmale supérieure, PSL University, 75005 Paris, France \\ ${ }^{\mathrm{b}}$ Inserm U955, Institut Mondor de Recherche Biomédicale, Equipe E01 NeuroPsychologie Interventionnelle, 94000 Créteil, France \\ c Université Paris-Est Créteil, Fa culté de médecine, 94000 Créteil, France \\ ${ }^{\mathrm{d}}$ Assistance Publique-Hô pitaux de Paris, National Reference Center for Huntington's Disease, Neurology Department, Henri Mo ndor-Albert Chenevier Ho spital, \\ Créteil, France
}

\section{A R T I C L E I N F O}

\section{Keywords:}

Striatum

Language

Huntington's disease

\begin{abstract}
A B S T R A C T
More than a century ago, Broca (1861), Wernicke (1874) and Lich teim (1885) laid the foundations for the first anatomo-functional model of language, secondarily enriched by Geschwind (1967), leading to the Broca-Wernicke-Lich teim-Geschwind model. This model included the frontal, parietal, and temporal cortices as well as a subcortical structure, which could be the striatum, whose nature and role have remained unclear. Although the em ergence of language deficits in patients with striatal injury has challenged the cortical language models developed over the past 30 years, the integration of the striatum into language processing models remains rare. The main argument for not including the striatum in language processing is that the disorders observed in patients with striatal dysfunction may result from the striatal role in cognitive functions beyond language, and not from the impairment of language itself. Indeed, un raveling the role of the striatum and the frontal cortex, linked by the fronto-striatal pathway, is a challenge. Here, we first reviewed the studies that explored the link between striatal functions and the different levels of language (phonetics, phonology, morphology, syntax, and lexico-semantics). We then looked at the language models, which included the striatum, and found that none of them captured the diversity of experimental data in this area. Finally, we propose an integrative anatomo-functional model of language processing combining traditional language processing levels and some "executive" functions, known to improve the efficiency and fluidity of language: control, working memory, and attention. We argue that within this integrative model, the striatum is a central node of a verbal executive network that regulates, monitors, and controls the allocations of limited cognitive resources (verbal working memory and verbal attention), whatever the language level. This model combines data from neurology, psycholinguistics, and cognitive science.
\end{abstract}

\section{Introduction: Language without striatum, a historical perspective}

The question of the role of the basal ganglia - more specifically the striatum - in language, began years ago, but it is only recently that its role in language reached sufficient interest to trigger new lines of experiments and models. The striatum (or neostriatum) is a subregion of the basal ganglia including a group of subcortical nuclei located at the base of the forebrain, linked to the cerebral cortex through both direct and indirect connections via the thalamus (Catani \& Thiebaut de Schotten, 2012). It consists of the caudate nucleus, the putamen, and the ventral striatum, the output of which is the palleostriatum or globus pallidus. Its central position in the brain makes it an excellent candidate for the convergence site of anterior and posterior language-processing networks.

The first models of language processing which involved the Broca (left inferior frontal gyrus) and Wernicke (posterior part of the left superior temporal gyrus and left supramarginal gyrus) areas of language (Broca, 1861; Wernicke, 1874), implied a subcortical structure, containing the "image" of words - the current semantics - in the so-called "model of the house" for aphasia (Lichteim, 1885). Later on, Geschwind (1967) who acknowledged the role of the Broca area in production, of the Wernicke area in comprehension, of the arcuate fa sciculus in repetition, disclaimed that a subcortical structure homed semantics, and instead proposed the implication of the inferior part of the parietal lobe for semantic processing. These successive contributions led

\footnotetext{
th This paper is a part of special issue "Special Issue in Honour of Jacques Mehler, Cognition's founding editor".

* Correspond ing author at: Service de neurologie, Hôpital Henri Mondor, 54 avenue du Général de Lattre de Tassigny, 94010 Créteil, France.

E-mail address: bachoud@gmail.com (A-C Bachoud-Lévi).
} 
to the so-called Broca-Wernicke-Lichtheim-Geschwind model, based on the distinction between comprehension and production in aphasic patients, which launched the domain of language processing. However, this has resulted in no longer considering the role of a puta tive subcortical structure and has put the focus on cortical structures and their connections (Ben Shalom \& Poeppel, 2008; Hickok \& Poeppel, 2004; Price, 2012). Subsequently, functional anatomical proposals converged on the neurofunctional organization of the left hemisphere cortices (Friederici, 2002; Hagoort, 2013; Hickok \& Poeppel, 2004; Indefrey \& Levelt, 2004; Jacquemot, Pallier, LeBihan, Dehaene, \& Dupoux, 2003; Leminen, Smolka, Duñabeitia, \& Pliatsikas, 2019; Price, 2012).

Leaving aside the decomposition betw een comprehension and production modalities, more recent studies provided functional models of language based on linguistic units (articulatory features, phonemes, morphemes, lexicon, and sentences) and rules that combine or break down these units at each level (Chomsky, 1965; Pinker \& Prince, 1994), while interacting with cognitive resources: working memory (Cowan, 2010; Jacquemot \& Scott, 2006), attention (Astheimer \& Sanders, 2009), and executive control (Fedorenko, 2014) (Fig. 1A).

In these models, phonetics deals with the acoustic properties of speech sounds and how they are articulated. It is associated with both the left premotor cortex and the supplementary motor area (Pulvermuller et al., 2006) (Fig. 1B). Phonology defines the distinctive features of speech sounds that combine into phonemes and how phonemes combine into syllables. Its processing is carried out in the left hemisphere, in the superior temporal gyrus/sulcus, inferior frontal gyrus, supplementary motor area, and insula (Hickok \& Poeppel, 2004; Jacquemot et al., 2003; Poeppel, 2014). Morphology defines the rules for combining phonemes into morphemes within the lexical units. Lexical units are the repertoire of words in a language, the lexicon. The lexicon and morphological processing are processed in the left middle temporal gyrus, supramarginal gyrus, and left inferior frontal gyrus (Devauchelle, Oppenheim, Rizzi, Dehaene, \& Pallier, 2009; Pallier, Devauchelle, \& Dehaene, 2011; Price, 2012). Syntax defines the rules for combining lexical units into sentences and relates to the left inferior frontal gyrus (Pattamadilok, Dehaene, \& Pallier, 2016). The meaning of sentences is encoded through the combination of the syntactic structure and the semantic content associated with the lexical units (Caramazza, 1997). Semantic memory involves the anterior part of the temporal cortices while the access, selection, and retrieval of semantic information are processed in the left angular gyrus, middle temporal gyrus, and inferior frontal gyrus (Chatrchyan et al., 2014; Hoffman, Binney, \& Lambon Ralph, 2015; Patterson, Nestor, \& Rogers, 2007; Vandenberghe, Price, Wise, Josephs, \& Frackowiak, 1996), leaving the striatum aside.

These anatomo-functional views appeared operational for many years until both the report of patients with brain lesions encompassing the striatum developing language disorders, and of imaging studies showing activation of the striatum during language processing experiments. Such observations could not be explained in the framework of classical cortical models and brought attention toward striatal functions, questioning the well-established view of a striatum dedicated solely to the motor function (Heimer, Switzer, \& Van Hoesen, 1982).

\section{Why should the striatum be integrated into language processing?}

In the 1970s, Cambier, Elghozi, and Strube (1979) described an aphasic patient with speech production disorders following a stroke affecting the left caudate nucleus. Their language was disturbed by perseverations, semantic inconsistencies, morphological paraphasias, and was disfluent, passing from one topic to another. Other cases of aphasia due to striatal lesions were described after this princeps report, suggesting that the subcortical structures and connections betw een the cortical and subcortical systems interfere with language processing (Cappa,
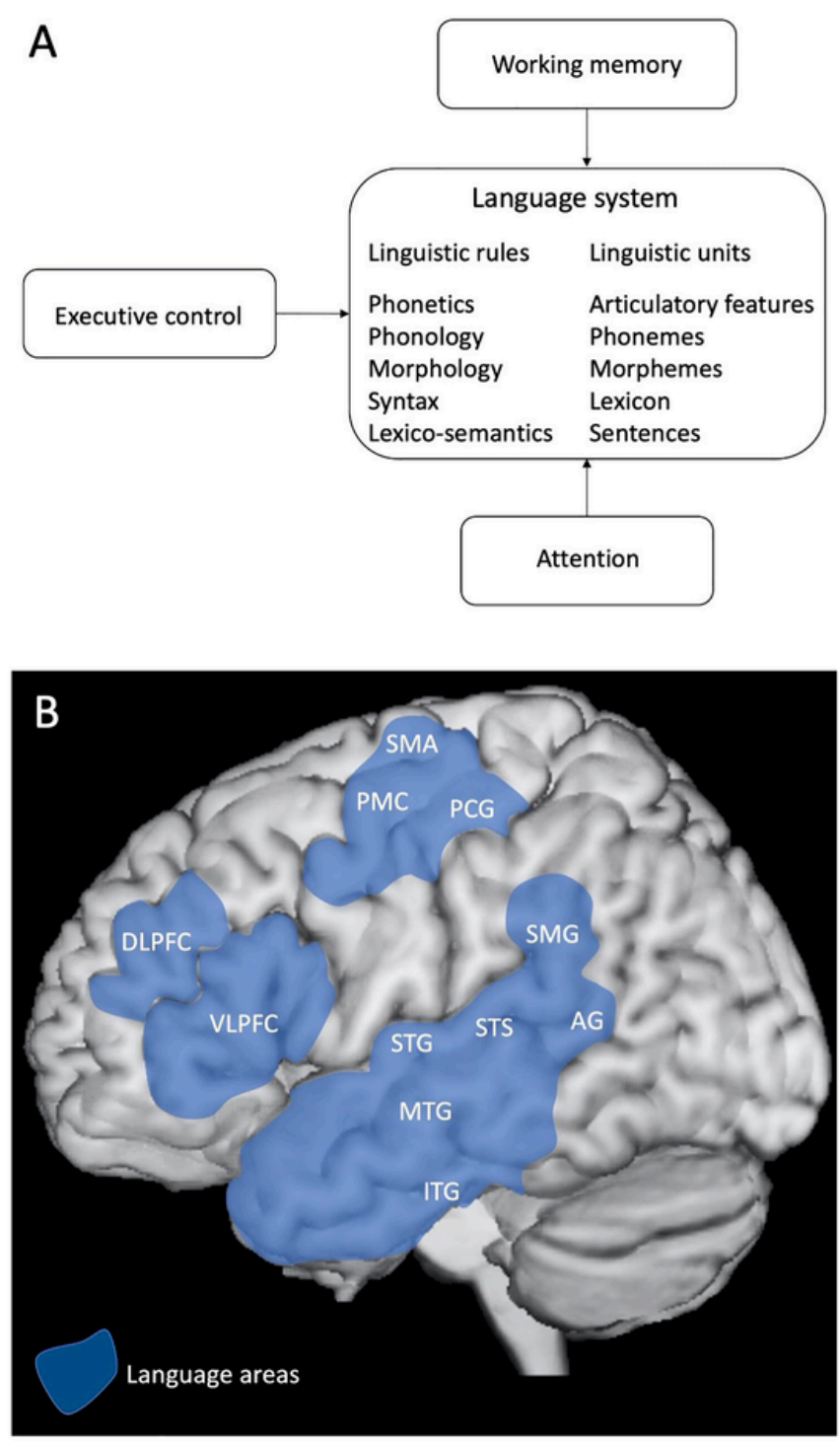

Fig. 1. Classical functional and anatomical model of language processing. A: Classical functional model of the language system including phonetics (repertoire of articulatory program), phonology (set of speech sounds), morphology (how the sounds combine to form words), syntax (how words combine to form sentences) and lexico-semantics (words and their meaning) B. An atomical model of language areas in the left hemisphere. Phonetics is associated with PMC and SMA (Pulvermuller et al., 2006) Phonology is associated with the STG/STS, IFG, SMA and the insula (Hickok \& Poep pel, 2004; Jacquemot et al., 2003; Poeppel, 2014). Morphology and words are associated with the MTG, SMG and IFG (Devauchelle et al., 2009; Pallier et al., 2011; Price, 2012). Syntax is associated with the IFG (Pattamadilok et al., 2016). Lexico-semantics is associated with the anterior part of the temporal cortex, the AG, MTG and (Chatrchyan et al., 2014; Hoffman et al., 2015; Patterson et al., 2007; Vandenberghe et al., 1996).

AG: angular gyrus, DLPFC: dorsolateral prefrontal cortex, IFG: inferior frontal gyrus, ITG: inferior temporal gyrus, MTG: middle temporal gyrus, PCG: precentral gyrus, PMC: Premotor cortex, SMA: supplementary motor area, SMG: supramarginal gyrus, STG: superior temporal gyrus, STS: superior temporal sulcus, VLPFC: Ventrolateral prefrontal cortex.

Cavallotti, Guidotti, Papagno, \& Vignolo, 1983; Damasio, Damasio, Rizzo, Varney, \& Gersh, 1982; Pickett, Kuniholm, Protopapas, Friedman, \& Lieberman, 1998). Subsequent studies yielded a more contrasted picture. In a review on subcortical aphasia, Nadeau and Crosson (1997) showed that even if some patients with putamen or 
caudate lesions did present an aphasic profile, most of them did not. In contrast, a study of 107 patients with aphasia after stroke showed that most lesions encompassing the putamen were associated with mutism and spontaneous poor fluidity, while those encompassing the caudate nucleus were associated with perseverations and lexical paraphasia (Kreisler et al., 2000). Consistently, in a cohort of 34 patients with acute ischemic stroke with impaired speech and language, while only a quarter of patients had their Wernicke and Broca regions af fected, most patients had an injury that included the left caudate nucleus and the adjacent radiata crown (Grönholm, Roll, Horne, Sundgren, \& Lindgren, 2016). Additionally, language rehabilitation outcomes in aphasic patients are correlated to the size of the striatal lesion (Crosson et al., 2007). Larger lesions of the striatum predicted worse rehabilitation outcomes than smaller lesions suggesting that the striatum interferes with language processing.

In parallel, connectivity and functional studies with healthy participants also showed that the language network should be extended to the striatal region. A meta-analysis of resting-state functional connectivity including 970 participants confirmed that the Broca and Wernicke areas are part of a network comprising the inferior frontal gyrus (pars triangularis, pars orbitalis, and pars opercularis), middle frontal gyrus, supramarginal gyrus, parieto-temporal gyrus, superior temporal gyrus, inferior parietal cortex, and bilateral caudate and left putamen (Tomasi \& Volkow, 2012;). Results of a brain imaging meta-analysis study including 71 studies with language tasks showed that the left putamen coactivated with the language network (inferior and middle frontal gyri, superior and middle temporal gyri, cingulate, and premotor cortex). They emphasize that the striatum should be integrated into anatomo-functional models of language.

Studies in patients with degenerative disorders have provided a large amount of information and have helped to identify the roles of the striatum, in particular its contribution to language processing. These studies mainly relied on Huntington's (HD) and Parkinson's (PD) diseases, both characterized by striatal dysfunctions. The study of these diseases makes it possible to evaluate relatively homogeneous groups of patients, unlike the collection of unique cases in patients with stroke. PD causes fronto-striatal dysfunction due to dopaminergic denervation of the caudate nucleus. By recording neuronal activity from deep electrodes located in the head of the caudate in these patients, Abdullaev and Melnichuk (1997) showed that the firing rate of the caudate cells was increased when language processes were required. The firing response was observed in these cells, with different time windows according to the task - semantic, naming, and reading tasks. The pattern of caudate-firing responses was similar to the neuronal responses of cells in Broca's area (Broadmann Area (BA) 44) (Bechtereva, Abdullaev, \& Medvedev, 1991), thereby suggesting that the caudate head and the Broca's area are connected, and both involved in language processing. On the other hand, HD is an inherited neurodegenerative disease, caused by an expansion of the CAG (cytosine-adenine-guanine) triplet repeats in the gene encoding the huntingtin protein. The mutant form of this protein accumulates in the regions of the brain leading to cell death (Macdonald et al., 1993). Although HD ultimately impacts the entire brain, atrophy affects the striatum early (Vonsattel et al., 1985) caudate atrophy being the best marker of disease progression (Tabrizi et al., 2012). Former descriptions of language disorders in HD have focused on speech, in line with studies of the role of the striatum in the motor system. Indeed, the striatum exerts an inhibitory influence on several motor functions, and the release of this inhibition allows motor activation. In HD, the deficit of the inhibitory system leads to involuntary choreatic movements, psychomotor slowing, and reduced agility of eye movements and articulation (Snowden, 2017). Dysarthria is usually the first symptom reported in these patients (Diehl et al., 2019; Podoll, Caspary, Lange, \& Noth, 1988). Speech rate correlates with motor impairment as, for example, tapping ability in a quantitative motor assessment (Skodda et al., 2014, 2016). The speech of patients in the early stages of HD differs from that of healthy controls: they have speech initiation disorders with a longer delay producing words and display pauses between and within words, compared to controls (Ludlow, Connor, \& Bassich, 1987; Vogel, Shirbin, Churchyard, \& Stout, 2012). Even in carriers of the genetic mutation without overt motor manifestation (so-called premanifest participants, or preHD), speech is characterized by impaired agility, slowing down, and phonatory dysfunction (Chan, Stout, \& Vogel, 2019; Riad et al., 2020; Rusz, Saft, Schlegel, Hoffman, \& Skodda, 2014). In contrast, in PD, the inhibitory system is increased, leading to reduced movement with hypophonia associated with hypernasality (Novotný et al., 2016). In this population, dysarthria is correlated with syntax comprehension difficulties, suggesting that the prefrontal cortex (known to be partially involved in these language components) is regulated through subcortical basal ganglia pathway (Lieberman et al., 1992). Likewise, reduced verb production compared to their noun production performance was interpreted in relation to their hypomotility (Péran, Démonet, Pernet, \& Cardebat, 2004).

Additional pieces came from several domains. Genetic studies identified the FOXP2 gene in the KE family suffering from developmental dysphasia (MacDermot et al., 2005). Half of its members had severe language disorders. They displayed poor performance in lexical decision, picture naming, sentence comprehension, word and nonword repetition, verbal fluency, non-word reading, inflectional and derivational morphology, and past-tense production (Watkins, Dronkers, \& VarghaKhadem, 2002). Both speech repetition disorders and nonverbal deficits in executive functions correlated with caudate nucleus volume (Watkins et al., 2002). Likewise, children with specific language impairment (SLI), a developmental disorder that results from the combined influence of the environment and multiple genetic variants, showed striatal structural and functional abnormalities (Krishnan, Watkins, \& Bishop, 2016). Despite a heterogeneous profile, an alteration of linguistic rules such as syntax, morphology, and often phonology are observed in the majority of children with SLI (Krishnan et al., 2016; van der Lely, 2005). Children with SLI also performed worse than their peers on the language procedural learning tasks which implicate corticostriatal learning circuits (Krishnan et al., 2016; Liljeholm \& O'Doherty, 2012).

These data substantiate the involvement of the striatum in language processes. However, since these data come from different fields that do not interact much, they enrich this enigmatic picture without creating a unified model. Systematic explorations of the role of the striatum in language have therefore been conducted to better understand the role of the striatum in language.

\section{Striatum and language processing experiments}

The previous studies were convincing enough to trigger experiments exploring the specific role of the striatum in language processing. They yield various conclusions; some suggest that the striatum may play a genuine role at some level of language processing, while others indicate that attention and executive control handled by networks involving the striatum may have an impact on languag e processing.

\subsection{Phonetics}

Using picture-naming tasks during awake craniotomy of gliomas, Robles, Gatignol, Capelle, Mitchell, and Duffau (2005) identified lateralized speech disorders associated with striatal stimulation. Direct electrical stimulation of the dominant putamen induced the inhibition of articulatory sequences. Stimulation of the dominant caudate elicited the production of perseverations, which suggests an executive control disorder. Speech deficits were specific to articulation and independent from motor deficit, as demonstrated by concomitant movements assessment of the contralateral hand during the task. These findings were 
consistent with a study assessing overt speech production and speech without overt sounds (inner or mouthed speech), showing the activation of the left putamen while articulating (Nota \& Honda, 2004). Consistently, multilinguals have higher grey matter density in the left putamen when compared to monolinguals, which is related to the mastering of articulatory repertoires from several languages (Abutalebi et al., 2013). In a speech repetition study combining PET, fMRI, and DTI data, the coupling between the speech-related dopamine release and the neural activity in the putamen, which receives descending laryngeal motor cortical projections, suggests the functional importance of the putamen in speech motor control (Simonyan, Herscovitch, \& Horwitz, 2013).

Acknowledging the role of control, coordination, and fluidity of voluntary movements by the striatum (Heimer et al., 1982), Ludlow et al. (1987) interpreted dysarthria in patients with HD, not as a linguistic deficit per se, but as a lack of control of the articulatory system concerning their striatal dysfunction, as are choreatic movements. In stuttering, another disorder af fecting the production of speech flow related to striatal dysfunction, the speech output is disrupted by involuntary repetitions and prolongations of sounds, syllables, words, or phrases as well as involuntary silence without any identified motor deficit (Lawrence \& Barclay III, 1998). Striatal activity correlates with stuttering severity and is modulated by speech improvement through fluency-shaping therapy (Giraud et al., 2008). Striatal dysfunction appears to affect self-generated movements and inhibition of competing involuntary movements in language, suggesting that the striatum may be involved in executive control of the speech motor program.

In professional interpreters mastering at least three languages, simultaneous interpretation was compared to simultaneous shadowing (Hervais-Adelman, Moser-Mercer, Michel, \& Golestani, 2015). Both interpretation and shadowing require the real-time conversion of the input stream from one language to another. They depend on multiple cognitive processes: continuous attention to the incoming speech flow, as well as planning, executing, monitoring, and correcting the speech output. Some processes are only relevant for interpretation but not for shadowing: semantic and syntactic analysis of the input, rapid translation in the other language with recovery of the appropriate lexical and syntactic forms. The left putamen was activated in both simultaneous interpretation and shadowing, adding evidence for its role in executive control of articulation in the appropriate language and in inhibiting the non-target language.

In brief, these experiments show that the striatum exerts control on the initiation of articulation, on the selection of the appropriate articulatory repertoire, as well as the inhibition of involuntary articulatory movements.

\subsection{Phonology}

Several studies have shown that the striatum interferes with phonological processing. Using a dopamine tracer in PET imaging, Tettamanti et al. (2005) evaluated striatal activity in healthy volunteers using acceptability judgments when reading non-words made from legal and illegal Italian phoneme strings. The accuracy of participants in detecting legal compared to non-legal phonological strings was modulated by the release of dopamine in the left caudate head: the poorer the accuracy of the phonological detection task (compared to a baseline condition with symbols instead of letters), the higher the level of dopamine release. To clarify whether the results are related to phonological deficits per se or to executive deficits, Teichmann, Darcy, Bachoud-Levi, and Dupoux (2009) assessed phonological perception in patients with HD through same-different judgments for pairs of words and non-words differing by a single phoneme. They contrasted two conditions - in the first one, HD patients had to discriminate two items (word or nonword) presented in isolation. In the second one, the second item was integrated into a long sentence either following or violating a phonological assimilation rule producing a phonemic transformation according to the phrasal context of the native language. The processing of the phonological units presented in isolation as well as the phonological assimilation rules was preserved in HD patients. However, their ability to discriminate words and non-words embedded in sentences was lower than that of the controls. As neither the processing of isolated phonological units nor the phonological rules were altered, a disorder of working memory or executive control probably explains their deficit in phonological discrimination tasks (Jacquemot, Dupoux, Decouche, \& Bachoud-Levi, 2006).

The analysis of errors and reaction times with drift-diff usion models allowed disentangling phonological processing from the executive component of the task (Le Stanc et al., 2020). HD patients displayed poorer performance compared to controls, and above all, make it possible to attribute their deficit to the executive component (attention) rather than to a phonological impairment.

Altogether, these studies suggest that the reduced attentional, monitoring and working memory resources observed in striatal disorders (Snowden, 2017) alter phonological unit processing.

\subsection{Morphology}

Following Cambier et al. (1979) who reported morphological paraphasias in a patient with left caudate stroke when the antonym was asked for (e.g., utile "useful" elicited desinutile "non-useless" with the duplication of the negative affixation), Ullman et al. (1997) evaluated inflectional morphology in patients with and without striatal dysfunction. They assessed verb conjuga tion from infinitive to past tense in several populations of patients with striatal dysfunction (HD and PD), and without striatal dysfunction (Alzheimer's disease and aphasic patients). In HD patients, they found excessive use of the default rule of inflection of regular verbs in English (for example, the verb to dig was conjugated as "digged" rather than "dug"). In parallel with the role of the striatum in motor programming and excessive motor activity in HD, Ullman et al. (1997) proposed that the striatum may play a comparable role in language rule programming with excessive use of morphological rules yielding to over-regularization. In contrast, patients with PD having a progressive inhibition of their voluntary movements, or akinesia, have reduced use of morphological rules (e.g., patients with unmarked conjugation keeping both dig or look in the conjugation past and present). Ullmann and his colleagues extended this comparison to patients with posterior and anterior aphasia or Alzheimer's disease by showing disturbances in the application of rules (despite an absence of abnormal movements) (Ullman et al., 1997). The role of the striatum was thus only attributed to the non-default rule of morphology excluding any role in default rules. It is worth noting that the model did not consider the slight difficulties of patients with the conjugation of regular verbs that respect the default rule.

Subsequent studies provided a contrasted picture. Some of them were consistent with a deficit of morphological rules in patients with striatal disorder, whereas others contradicted this hypothesis. Teichmann et al. (2005) replicated these morphological deficits in a larger group of French HD patients during the conjugation of verbs and non-verbs in the present and future tense. They showed that, unlike controls, HD patients conjuga te sub-regular non-verbs (supposed to respect non-preeminent French rules, for example in -oir or -ir) by adopting the most prominent French rule in -er (for example, the non-word choupoir was mainly conjugated in choupera in the future rather than in choupoira). How ever, like Ullman et al. (1997), they did not consider the results of the slight deficit of sub-regular verbs, which could have been retrieved from memory rather than by the application of rules. This confirms that the striatum is involved in regular and irregular morphology, even if it appears more pronounced with less frequent rules. Consistently, a PET study showed that performance in both regular and subregular morphological rules of French was correlated with the me- 
tabolism of the different parts of the striatum (Teichmann et al., 2008). In a task of judgment of acceptability in perception, the overregularized non-verbs were more accepted than those following the non-preeminent rule of French in -oir for example (Teichmann, Dupoux, Kouider, \& Bachoud-Lévi, 2006). Likewise, Nemeth et al. (2008) observed morphological errors in the derivation of Hungarian nouns in asymptomatic carriers of the mutant huntingtin gene (before the onset of the motor symptoms), thus extending the impact of the striatum on rules to nouns, but also excluding any interaction between motor and morphological disorders.

On the other hand, in HD, Longworth, Keenan, Barker, MarslenWilson, and Tyler (2005) excluded an association between striatal dysfunction and the alteration of the morphological rules in conjugation, either in comprehension or in production. Using past tense elicitation tasks, they observed errors in regular and irregular forms, suggesting a general deficit in morphological production regardless of verb regularity. The patients' most frequent error was to produce semantically related verbs with the correct inflection (e.g., banged rather than slammed) rather than a wrong inflection of the target verb. Such an inability to suppress semantic alternatives indicates a deficit of executive control to inhibit the competing alternative and/or a true semantic disorder. These hypotheses were evaluated in morphological tasks using the inflection of adjectives (Giavazzi et al., 2018). French HD patients were asked to generate the masculine from the feminine form of pseudo-adjectives. The patients did not produce illegal or aberrant morphological forms but did not produce the correct ones. Mathematical modeling of the errors suggested a deficit in the selection, rather than the evaluation, of the alternative forms. In other words, patients were able to generate the correct answers in most cases, but sometimes they chose the most frequent rules rather than the correct ones. Their linguistic performance was correlated with caudate nucleus volume, suggesting its involvement in linguistic selection. In a verbal production task, patients with PD showed a different error profile according to morphological differences (derived and default position, present and past tense, transitive, and intransitive forms). Their performance was correlated with their executive and working memory performance, suggesting that executive functions underlie their verbal production capacities (Colman et al., 2009).

Finally, de Diego Balaguer, Costa, Sebastian-Galles, Juncadella, and Caramazza (2004) showed that HD patients were altered when learning morphological rules. When listening to auditory syllable sequences, participants had to pay attention to the characteristics of verbal stimuli, monitor the likelihood of morpheme transitioning, and switch to other stimuli to identify repeated words or infer certain morphological rules. Their learning disabilities were correlated with caudate atrophy. HD patients' disorder in the process of disengagement and set-shifting (Couette, Bachoud-Levi, Brugieres, Sieroff, \& Bartolomeo, 2008) could explain their difficulties in learning new rules (Rogers, Andrews, Grasby, Brooks, \& Robbins, 2000).

Morphological tasks are impaired in patients with striatal dysfunction. In most cases, patients do not produce aberrant but legal morphological forms, which correspond to the most common morphological rules of their language. In other cases, they produced alternative semantic words. The morphological deficit is better explained by an executive impairment including inhibition, selection, monitoring, and setshifting rather than by a deficit in the processing of morphological units.

\subsection{Syntax}

Contrasting phonotactic, morphological, and syntactic violations, a PET study in healthy participants found that while Broca's area was consistently involved in the acceptability judgment of all kinds of violations, the left caudate nucleus and insula were activa ted only for syntactic violations, indicating their role in syntactic computation (Moro et al., 2001). The role in syntactic computation of the striatum was therefore explored in a study contrasting the comprehension of active and passive sentences in French (Teichmann et al., 2005). HD patients were impaired with passive sentences but flawless in active ones, suggesting that the striatum contributes to the syntactic processing of sentences not following the canonical order of French, requiring "word reordering" transformation. This syntactic impairment correlated specifically with striatal atrophy (Teichmann et al., 2005). However, both performance with canonical and non-canonical sentence metabolism correlated with different parts of striatal metabolism, thus indicating that the striatum is involved in all types of syntactic structures (Teichmann, Gaura, et al., 2008). The anatomical pathway connecting the striatum to Broca's area was further explored using a lesion-based approach to mapping white matter disconnection in patients with frontal / striatal lesions after a glioma post-surgical resection (Teichmann et al., 2015). They showed that the integrity of the tract connecting BA 44/45 to the left caudate head is essential to accurately perform these syntactic tasks. No such anatomo-clinical association was observed in morphological or phonological tasks. These results add a deep "Broca-caudate pathway" of BA44 / 45 to current models of the left caudate head, involved in syntactic processing and more specifically in the complex computation necessary for the transformational reorganization of words (Teichmann et al., 2015). The existence of this deep fronto-striatal pathway may explain why some patients with striatal injury behave like patients with Broca's aphasia (Bohsali \& Crosson, 2016).

Syntactic processing relies in part on verbal working memory and executive control resources to manipulate stored input and rearrange word order (Caplan \& Waters, 1999; Fiebach, Schlesewsky, Lohmann, Von Cramon, \& Friederici, 2005; Makuuchi, Grodzinsky, Amunts, Santi, \& Friederici, 2013). To disentangle memory capacity and syntactic processing, Sambin, Teichmann, Sportiche, Schlenker, and Bachoud-Lévi (2012) contrasted several types of syntactic structures that did or did not allow for the coreference between the noun and the pronoun while keeping distance and working memory load constant betw een the noun and the pronoun. Patients with HD were impaired in comprehending certain syntactic co-reference rules independently of the working memory load. In contrast, their performances were normal in gender agreement, regardless of the distance between the noun and the adjective. The authors concluded that the striatum is involved in certain syntactic rules involving complex calculation and that the syntactic deficits observed in patients were not based on deficits in working memory (Sambin et al., 2012). These results were replicated in speech production when assessing coreference (and to a lesser extent gender agreement) in verbal storytelling by HD patients (Hinzen et al., 2018).

The role of the striatum in controlled versus automatic syntactic processing was further explored using evoked response potential (ERP) techniques in patients with brain lesions. For instance, when the verb information does not license the syntactic structure, patients with striatal dysfunction do not show the expected late positivity P600 reflecting controlled syntactic processes (Friederici, Von Cramon, \& Kotz, 1999, 2003; Kotz, Frisch, Von Cramon, \& Friederici, 2003). Likewise, the striatum of a healthy participant is activated as soon as the automatic processes are insufficient for a satisfactory comprehension of the sentences in a task of judging the grammaticality of unambiguous, ungrammatical, and ambiguous sentences (Mestres-Misse, Turner, \& Friederici, 2012). The pattern of activation of the left striatum differs according to the types of sentences. Ambiguous and ungrammatical sentences elicit greater activation of the postero-dorsal part of the caudate head and the dorsal and ventral prefrontal cortex, compared to unambiguous sentences. Conversely, ambiguous sentences mainly activate the left antero-ventral part of the caudate head and the left anterior prefrontal cortex compared to ungrammatical sentences. The authors proposed that the striatum is recruited when the sentences conflict 
with the automatic response and require high-level executive control. They showed the existence of an antero-posterior syntactic gradient in the head of the caudate nucleus, from the simplest syntactic computation in the postero-dorsal to the most complex computation in the antero-ventral portion of the caudate.

Altogether, these studies show that the striatum is involved in syntactic processing. They indicate a deficit in executive control of syntactic processing rather than a loss of syntactic knowledge with a gradient within the striatum according to the level of complexity of syntactic processing.

\subsection{Lexico-semantics}

Lexico-semantic, morpho-syntactic, and phonological information related to a word constitute connected but independent levels of representation and are stored in separate networks (Caramazza, 1997). Lexical units include the catalogue of words: the lexicon. The semantic system which encodes the conceptual knowledge and semantic memory (the events of life) is independent from language but can be accessed through it (Patterson et al., 2007). Lexico-semantics relates to the meaning of the lexical units according to the syntactic structure of the sentences and is part of the language system.

There are many arguments for attributing a role of the striatum in lexico-semantic processing. First, recording the firing rate of cells in the head of the caudate in PD patients showed that the cells' firing rate was increased within a 400-600 msec window in situations involving lexico-semantic process: reading words rather than pseudowords in a lexical decision task, semantic decision (concrete vs abstract) rather than only reading words, and naming objects compared to control motor condition (Abdullaev \& Melnichuk, 1997). In stroke patients with striatal lesion, lexical errors in picture naming and spontaneous speech consisted in perseverations, semantic paraphasia (Thermometer being named Thermostat, Lion instead of Wolf in the little red riding hood story), and even fantastic paraphasia with for instance the fringe of a scarf named a boa with bells to put around the neck (Cambier et al., 1979; Cappa et al., 1983). HD patients produced fewer content words than healthy controls in a picture description task (Gordon \& Illes, 1987). They also had low performance in both categorical and lexical fluency. In these tasks they are asked to produce, in one or two minutes, as many items as they could in a category (e.g., animals), or beginning with a specific letter (Lawrence et al., 1998). Their performance pattern suggests that the striatum is required for switching betw een competing lexical items (Snowden, 2017) and points towa rd a disengaging and set-shifting disorder in HD's patients, as in the visual domain (Couette et al., 2008). For example, a trilingual patient with a stroke lesion affecting the white matter surrounding the head of the left caudate nucleus could not prevent herself from switching from one language to another in a picture-naming production task, suggesting that this part of the caudate nucleus is involved in speech control (Abutalebi, Miozzo, \& Cappa, 2000). In a priming paradigm, the activation of the left caudate head was greater for semantically related prime and target words from different languages than within the same language in proficient bilingual individuals (Crinion et al., 2006). These data from multilingual participants suggest that the left caudate head has a critical role in executively demanding situations of lexico-semantic processing. In multilingual simultaneous interpreter experts, the caudate nucleus was also more activated in simultaneous interpretation conditions which require the overarching selection and control of the lexicosemantic system than in the shadowing condition (Hervais-Adelman et al., 2015). In contrast, in some comprehension ta sks, the recovery of semantic information does not seem affected by striatal dysfunction. HD patients flawlessly process idiomatic sentences that involve lexical access to a whole phrase such as It is raining cats and dogs (Teichmann, Dupoux, Cesaro, \& Bachoud-Levi, 2008). Presumably, because idioms are stored as a whole, the lexical competition may be reduced in this case. The striatum would be more involved in lexico-semantic tasks requiring high executive control demand.

Altogether, the left caudate head has a critical role in executively demanding situations of lexico-semantic processing when dealing with high competition between items. The striatum appears involved in the control, manipulation, and selection of lexical items rather than in their storage.

\section{Models of the striatal impact on language processing}

While the number of experiments assessing the role of the striatum in language has increased tremendously, models remain scarce, and none take into account the contrastive view displayed by the recent studies. Here, we review these models before attempting to provide a unified view.

\subsection{The declarative/procedural dichotomy}

The first dedicated model to language processing integrating the striatum as a major component was provided by Ullman (2001). As previously stated, he argued for an association between motor disorders, striatal dysfunction, and language deficit in patients. By proposing that the over-regularization of the conjugation of verbs is linked to HD chorea while the decrease in the application of rules to the reduction of movements in PD, he generalized the results obtained in morphology to the linguistic system. He, thus, proposed the "declarative / procedural model" in which the mental lexicon depends on the declarative memory lodged in the temporal lobe and on the procedural component of the rules of language, the mental grammar. This latter component involves procedural memory, in relation to motor programming within the fronto-striatal network (Ullman, 2001). The distinction between declarative and procedural memory is reminiscent of studies exploring the object (noun) and action (verbs) dissociations in aphasic patients. Indeed, most anomic patients with parieto-temporal lesions performed better with verbs than with nouns, while patients with frontal lesions displayed the reverse pattern (Miceli, Silveri, Villa, \& Caramazza, 1984). Since exceptions were reported, such as better naming performance with verbs compared to nouns despite fronto-parietal damage (Shapiro, Shelton, \& Caramazza, 2000) or verb impairments with spared frontal cortex (Silveri \& Di Betta, 1997), alternative explanations were provided for this potential dissociation. They include among others (1) the abstract/concrete dichotomy, verbs being more abstract than nouns (Bachoud-Lévi \& Dupoux, 2003), (2) the grammatical category segregation stipulating that because of their syntactic function verbs and nouns are processed in different brain areas (Laiacona \& Caramazza, 2004; Shapiro \& Caramazza, 2003), (3) the sensory/functional account which posits that the dissociation between verbs and nouns is an effect of their sensory versus functional properties (McCarthy \& Warrington, 1985), and (4) the clustering of their common semantic features inducing a dissociation between actions and concepts into the brain (Da masio \& Tranel, 1993).

Ullman's declarative / procedural dichotomy hypothesis (Ullman, 2001) inspired many experiments in patients with striatal lesions, some of which have resulted in alternative models. However, as previously reported, not all linguistic rules were impaired in HD: phonological assimilation (Teichmann et al., 2009), gender inflection in adjectives (Giavazzi et al., 2018), and gender agreement (Sambin et al., 2012) were spared, thus contradicting this dichotomic view. Second, the dissociation between regular and irregular verbs failed to be replicated in several patients. In this view, regularity (application of rules) is handled by the procedural component and irregularity (stored in the mental lexicon) by the declarative component. However, even in the princeps studies (Teichmann et al., 2005; Ullman et al., 1997) both subregular and, to a lesser extent, regular rules were also impacted by striatal lesions, thereby discarding the dichotomic model. Likewise, worse per- 
formance in regular compared to irregular verbs and nouns would have been expected in Broca's aphasia and HD patients. Several studies of patients with Broca's aphasia display a contrastive pattern of dissociation between regular and irregular verbs (de Diego Balaguer et al., 2004; Fa roqi-Shah, 2007; Penke, Janssen, \& Krause, 1999). Even in HD, the dissociation between regular and irregular verbs and nouns wa not replicated (Longworth et al., 2005; Nemeth et al., 2012). Finally, errors such as fantastic paraphasia (Cambier et al., 1979), frequently observed in aphasic patients with striatal lesions, could not be explained in the declarative/procedural framework.

\subsection{Late syntactic integration hypothesis and cognitive control in syntax}

The functional neuro-imaging studies (ERPs, MEG, fMRI) in healthy participants and anatomo-clinical analysis on patients suffering from vascular or neurodegenerative lesions have identified four successive stages of language comprehension housed in the left hemisphere (Friederici, 2002; Friederici et al., 2003; Friederici, 2011; Friederici \& Kotz, 2003; Kotz et al., 2003). (1) The phonological and word form segmentation is processed in the auditory cortex and the superior temporal gyrus; (2) the syntactic structure building is associated with the superior temporal gyrus and the inferior frontal gyrus (BA 44); (3) the thematic role assignment and semantic relationships are processed in the middle temporal gyrus and the frontal lobe (BA 44/45 for the morphosyntax analysis and BA 44/45 for the semantic roles); (4) late processes of reanalysis and repair with syntactic integration, for instance when the verb information does not license the syntactic structure, involve a network connecting striatal, frontal and parietal areas (Friederici, 2002). In addition, the authors add working memory resources hosted in the inferior frontal gyrus (BA 44, 45/47, 44/45) and executive processes hosted in a fronto-striatal loop to the model, which sustains all steps of language and is part of this language network (Friederici, 2002). $R e$-analysis and repair processes through the parietostriatal network also involve attentional resources (Friederici, 2002; Friederici, 2006; Friederici \& Singer, 2015). Early automatic processes are spared in patients with $\mathrm{PD}$, whereas late integrational processes are impaired (Friederici et al., 2003; Friederici \& Kotz, 2003; Kotz et al., 2003). In complement, Mestres-Misse et al. (2012) proposed that the striatum is involved in processing all types of syntactic structures with increased control when the sentences become more complex. As syntactic complexity increases, the activation of the striatum slides from the postero-dorsal region to the antero-ventral region. This striatal gradient (with the more rostral part supporting higher and less automatic levels of syntactic comprehension than the caudal part) suggests that different regions of the striatum are involved in syntactic processing, depending on the level of language complexity.

Altogether these authors advocate that the striatum plays a crucial role in a network supporting working memory, at tentional, and executive resources required for re-analysis of sentence structure and semantic relations when automatic processes are not sufficient. However, whereas this proposal explains why some syntactic rules are more impaired than others, it does not ta ckle morphological rules in impairment of HD patients (Giavazzi et al., 2018; Sambin et al., 2012). It cannot explain why not only syntactic but also morphological performances correlate with parts of the striatum in both PET and MRI studies (Teichmann et al., 2005, 2006; Teichmann, Gaura, et al., 2008).

\subsection{The GODIVA computational model of speech motor control}

Other models based on neural network simulations, like the Directions Into Velocities of Articulators (DIVA) and the Gradient Order Directions Into Velocities of Articulators (GODIVA) models, focus specifically on the simulation of syllable production. They simulate phonological and phonetic outputs involving the inferior frontal sulcus and the pre-motor cortex, respectively (Guenther, Ghosh, \& Tourville, 2006).
According to these models, the putamen, connected to the supplementary motor area and the premotor cortex, contributes to the initiation of motor speech commands and the integration of sensorimotor information to initiate the commands for the next sound to be produced. The caudate intervenes in the planning loop of the phonological sequence via its connection to the pre-supplementary area and to the inferior frontal sulcus (Civier, Bullock, Max, \& Guenther, 2013; Guenther \& Hickok, 2016). These neural modeling approaches focused on the phonetics and phonological levels and did not tackle the other levels of language, thus precluding a unified view.

\section{The striatal control of language levels and verbal executive resources}

Although these previous hypotheses have been invaluable in integrating the striatum into the linguistic network, some adjustments are necessary to adapt them to the diversity of impact of striatal processing in language. Whereas the striatum seems involved in all language tasks, it particularly impacts the processing of irregular or infrequent stimuli that involve non-automatic process (Hinzen et al., 2018; Nemeth et al., 2012; Sambin et al., 2012; Teichmann et al., 2005; Teichmann, Dupoux, et al., 2008; Ullman et al., 1997), when selection, inhibition, and monitoring load is increased (Abutalebi et al., 2000; Aron et al., 2003; Crinion et al., 2006; Friederici et al., 2003; Giavazzi et al., 2018; Hervais-Adelman et al., 2015; Kotz et al., 2003; Longworth et al., 2005), or when set-shifting is needed (De Diego-Balaguer et al., 2008; Snow den, 2017). Morphological errors in HD patients may result from a deficit of the inhibition of competing alternatives (Longworth et al., 2005) or a deficit in the selection process between alternatives (Giavazzi et al., 2018).

The linguistic experiments reported above support the idea that the striatum intervenes at least when an automatic or default choice is not available, highlighting its role in executive control of language. This includes processes such as flexibility (the ability to shift attention focus including set-shifting), planning (the ability to organize a series of processes), and monitoring (the ability to memorize, update, inhibit and select information) that support all levels of language. The striatal neuronal loss follows a dorso-ventral gradient in HD (Kassubek et al., 2004). As the more executively demanding linguistic operations are processed in antero-ventral regions of the striatum (Mestres-Misse et al., 2012), it may explain why some linguistic processes such as syntax or morphology, are more affected in HD patients. The hypothesis of the striatal executive control of language also explains aphasic patients' findings (Kreisler et al., 2000). Non-fluent aphasia, associated with putamen lesion, may result from a disorder of the initiation component of the executive functions triggering the overt production of language. Verbal paraphasias and perseverations, associated to temporal and caudate lesions, are consistent with an inhibition disorder and an inability to select the best choice among competing alternatives, and disengagement and set-switching deficit respectively (Kreisler et al., 2000).

Disentangling the specific role of the striatum from the frontal lobe remains difficult because functional and white matter connectivity studies showed that the left inferior and middle frontal gyri are connected to both the caudate nucleus and the putamen (Bohsali \& Crosson, 2016; Catani \& Thiebaut de Schotten, 2012; Drag anski et al., 2008; Leh, Ptito, Chakravarty, \& Strafella, 2007; Lehéricy et al., 2004; Tomasi \& Volkow, 2012). Connectivity pathways link the caudate nucleus to the ventral lateral prefrontal cortex, and the putamen to the primary motor and premotor cortical regions (Leh et al., 2007; Lehéricy et al., 2004), with these cortical regions being involved in all levels of language processing. The premotor cortex and supplementary motor area (BA 6) are associated with phonetic processing (Pulvermuller et al., 2006). The inferior frontal cortex is divided up into three different territories: a dorsal part (BA 44/6) associated with phonology, a middle 
part (BA 45/44) associated with syntax, and a more inferior part (BA 47/45) associated with verbal semantic content (Amunts \& Zilles, 2006; Bookheimer, 2002; Hagoort, 2005). The left inferior frontal gyrus is also an activated region in tasks assessing morphological processing (Leminen et al., 2019) Within the fronto-striatal network, the striatum is involved in the executive control of each level of language (see Fig. 2).

In addition to the core languag e levels, verbal working memory and attention are resources needed for the language processing to be efficient (Astheimer \& Sanders, 2009; Brunia \& Van Boxtel, 2004; Cowan, 2010; Grossman, Carvell, Stern, Gollomp, \& Hurtig, 1992; Grossman, Lee, Morris, Stern, \& Hurtig, 2002; Jacquemot et al., 2006; Jacquemot, Dupoux, \& Bachoud-Levi, 2011; Jacquemot \& Scott, 2006; Pritchard \& Hendrickson, 1985). Their deficits are not only concomitant with language deficits but actually contribute to the very nature of those deficits (Colman et al., 2009; Jacquemot \& Scott, 2006; McNeil \& Pratt, 2001). At the phonological level, they allow for the segmentation of speech stream into words and the online syllabification in which the context needs to be continuously evaluated, and allow processing for monitoring complex sentences at the semantic and syntactic levels (Caplan \& Waters, 1999; Grossman et al., 2002; Indefrey \& Levelt, 2004; Jacquemot et al., 2006, 2011; Jacquemot \& Scott, 2006; Martin \& Romani, 1994).

Verbal working memory recruits brain regions of the language network, namely the left posterior superior temporal sulcus and supramarginal gy rus, the left ventrolateral prefrontal cortex, the supplementary motor area, and the insula (Jacquemot \& Scott, 2006). The activity of both prefrontal and caudate regions is associated with inter-individual differences in working memory capacity (McNab \& Klingberg, 2008). The caudate nucleus contributes to the control of working memory by monitoring the information maintained in verbal working memory (Lewis, Dove, Robbins, Barker, \& Owen, 2004; Niendam et al., 2012). This role has been shown through the impairment of HD patients in verbal memory tasks with high monitoring load (Teichmann et al., 2009). In a task requiring high working memory monitoring, HD patients show lower brain activation than controls in the left prefrontal cortex (both dorso- and ventrolateral regions), the left inferior parietal cortex, and the left striatum, with an activation plateau in the left striatum and left inferior frontal gyrus (BA 44) not observed in controls (Wolf,
Vasic, Schönfeldt-Lecuona, Ecker, \& Landwehrmeyer, 2009), thereby highlighting the role of the striatum in controlling the verbal working memory.

The striatum also contributes to the control of the verbal attention network which associates the left intraparietal sulcus, the temporoparietal junction, the left inferior frontal gyrus, and middle frontal gyrus (Pugh et al., 1996; Shaywitz et al., 2001). In a paradigm contrasting the monitoring of verbal and spatial attention, the head of the left caudate nucleus and the left anterior cingulate were more activated when monitoring verbal at tention, thus supporting their role in the control of verbal attention (Ali, Green, Kherif, Devlin, \& Price, 2010).

Altogether, the striatum seems an essential node within the left fronto-striatal network for not only the executive control of language levels but also of both verbal working memory and verbal attention.

\section{Toward an integrative language system}

The role of the striatum in language appears crucial in a conflicting situation or when the default rule is not available, thus explaining the discrepancy between the results of some previous studies. As an example, Nadeau and Crosson (1997) showed aphasic profile only in a few patients with striatal lesions whereas Kreisler et al. (2000) identified it as the major structure for predicting aphasia in brain lesions. This might rely partly on the numerous confounding variables of task demands, associated deficits, or imaging analyses. Our review shows that the striatum impacts all levels of language through their executive control with various involvement regarding the type of the task.

At the phonetic level, it allows to initiate articulation, select the appropriate articulatory forms and motor program, and inhibit involuntary movement (Abutalebi et al., 2013; Giraud et al., 2008; Hervais-Adelman et al., 2015; Nota \& Honda, 2004; Robles et al., 2005; Simonyan et al., 2013). At the phonological level, it updates and monitors the series of phonemes rather than processing phonological units per se (Le Stanc et al., 2020; Teichmann et al., 2009; Tettamanti et al., 2005). At the morphological level, striatal dysfunction leads to morphological legal or semantic errors and induces (in most cases) the use of the default rule which suggests a striatal role in selecting, inhibiting, monitoring, and set-shifting between the various morphological alternatives rather than in building morphemes

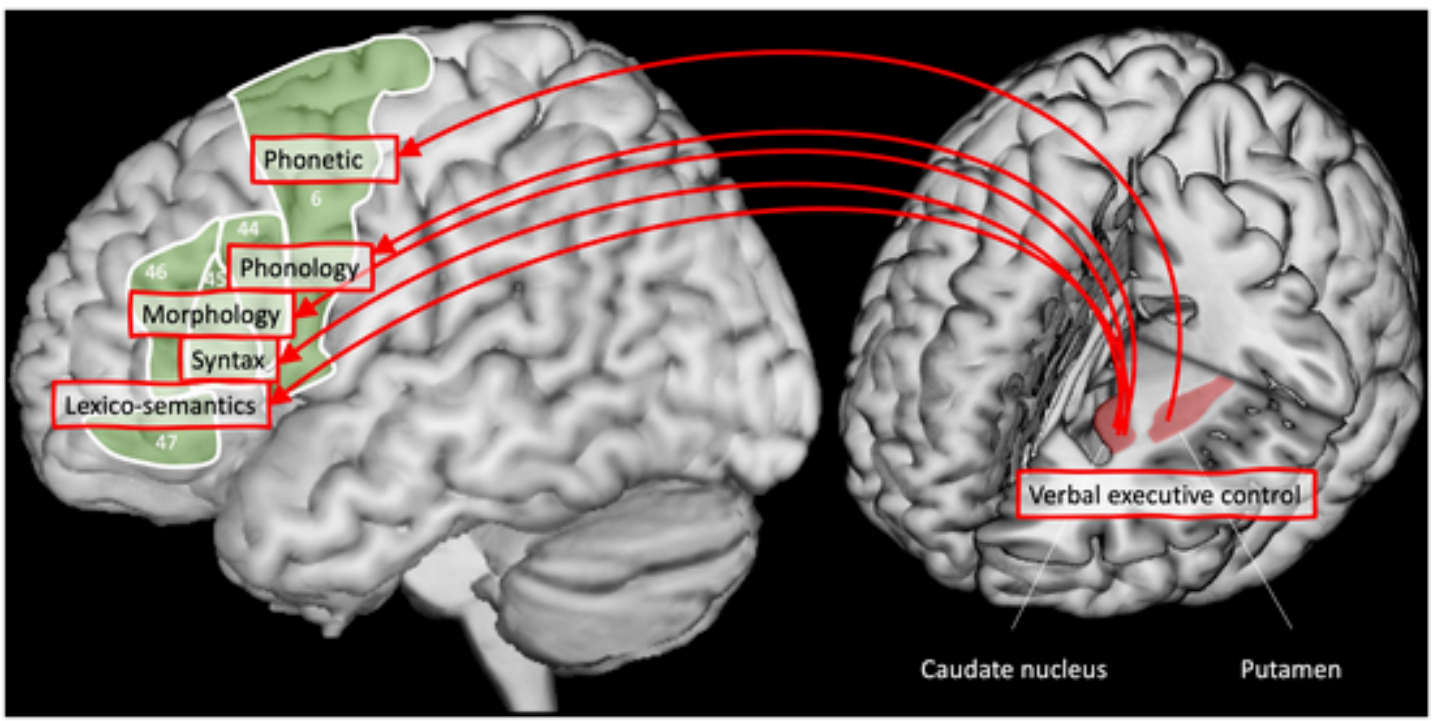

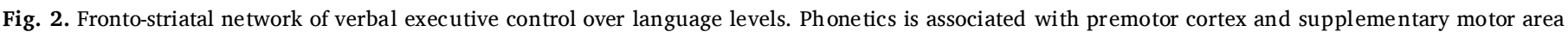

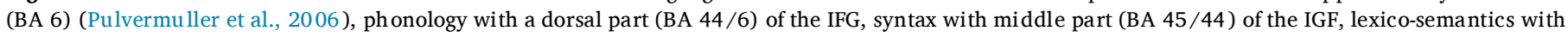

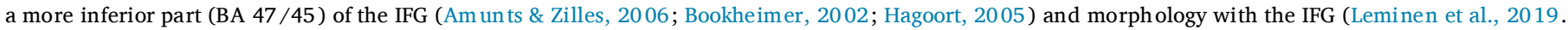

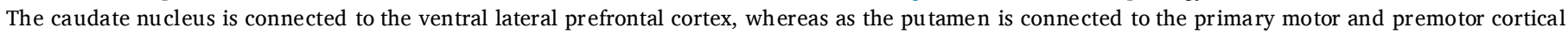
regions (Leh et al., 2007; Lehéricy et al., 2004). BA for Broadmann area. 
(Colman et al., 2009; De Diego-Balaguer et al., 2008; Giavazzi et al., 2018; Longworth et al., 2005; Nemeth et al., 2008; Teichmann et al., 2005, 2006; Ullman et al., 1997). Similarly, at the syntactic level, striatal dysfunction leads to syntactic interpretation errors that follow the canonical or most frequent syntactic order; thereby suggesting a role of the striatum in the executive control of the syntactic processing rather than of syntactic knowledge (Friederici et al., 2003; Hinzen et al., 2018; Kotz et al., 2003; Mestres-Misse et al., 2012; Moro et al., 2001; Sambin et al., 2012; Teichmann et al., 2005, 2015). Finally, at the lexico-semantic level, the striatum intervenes in executively demanding situations of lexical processing. It is required to select the proper linguistic alternative among others, to memorize, update, and monitor linguistic units when disambiguation or reanalysis is needed and to shift attention focus between stimuli to extract regularities (Abdullaev \& Melnichuk, 1997; Abutalebi et al., 2000; Cambier et al., 1979; Cappa et al., 1983; Crinion et al., 2006; Gordon \& Illes, 1987; Hervais-Adelman et al., 2015; Lawrence et al., 1998). Altogether, striatal dysfunction can induce language disturbances at all levels, not by affecting the processing of linguistic units and rules per se, but rather by damaging the manipulation of these units and rules and promoting the default form, when available, in conflicting situations. In ecological situations, during real-life exchanges, ambiguous situations often occur with mispronounced words, truncated sentences, syntactic errors, ambiguous context (for a review see Fedorenko, 2014). Presumably, the striatum is involved in language, whatever the task, through its role in executive control which participates in the efficiency and fluidity of language from simple to more complex linguistic situations,. This explains why in PET and fMRI imaging studies, various parts of the striatum are activated in tasks assessing phonetics, phonology, morphology, and syntax whatever the complexity of the target items (Giraud et al., 2008; Mestres-Misse et al., 2012; Teichmann et al., 2008). This involvement follows a gradient from simple linguistic situations requiring low executive demand and activating caudal regions to more complex situations requiring higher executive demand processed in more rostral regions (Mestres-Misse et al., 2012).

A further question is whether the role of the striatum in executive control is specific to language processing. Executive control is not limited to language processing and the striatum may be involved in executive control regardless of the domain. Executive control is often viewed as a domain-general process regulating not only language but also visual processing, arithmetic, and motor processing among others (Fedorenko, 2014). Indeed, executive abilities in the non-verbal domain correlate with performance in demanding language tasks in healthy participants (Shao, Roelofs, \& Meyer, 2012; Taler, Aaron, Steinmetz, \& Pisoni, 2010). Children with SLI displaying low nonverbal executive abilities are impaired in complex sentence processing (Im-Bolter, Johnson, \& Pascual-Leone, 2006; van der Lely, 2005). Multilinguism has advantages not only in verbal tasks (Bialystok \& Feng, 2009; Filippi et al., 2015; Filippi, Leech, Thomas, Green, \& Dick, 2012), but also in non-verbal tasks requiring executive control (Bialystok, Craik, \& Luk, 2012). Higher capacity of executive control mechanisms allows for filtering out verbal interference or compensating for weaker language proficiency (i.e., smaller vocabulary size of bilinguals as compared to the vocabulary size of monolinguals) and confers nonlinguistic skills too (Bialystok et al., 2012). The striatum is also involved in domain-general processes of response selection, response inhibition, and conflict monitoring (Botvinick, Cohen, \& Carter, 2004; Grahn, Parkinson, \& Owen, 2008). Both the right and left striatum are integrated into a network including the prefrontal, dorsal anterior cingulate, the superior parietal lobe, and the supramarginal gyrus dedicated to general executive control (Cocchi, Zalesky, Fornito, \& Mattingley, 2013; Monchi, Petrides, Strafella, Worsley, \& Doyon, 2006; Niendam et al., 2012; Provost, Petrides, Simard, \& Monchi,
2012). This network is altered in HD patients (Pini et al., 2020; Pini et al., 2020).

Here, we propose that some aspects of executive control are specific to language and that the striatum is a major node of this verbal executive control network. First, the advantage of multilingualism has been questioned in a growing number of studies showing similar performance between monolingual and multilingual participants in nonverbal reasoning (Duñabeitia et al., 2014; Filippi, Ceccolini, PericheTomas, Papageorgiou, \& Bright, 2020; Paap \& Greenberg, 2013; Paap, Johnson, \& Sa wi, 2014); factors not included in previous studies such as socio-economic status, for example, may have confounding effects (Lehtonen et al., 2018). In addition, verbal and non-verbal executive control can be impaired or spared independently in patients (Jacquemot \& Bachoud-Levi, 2021, in revision; Murray, 2017). When available, anatomical data of patients with executive deficit specific to language tasks, show lesions that include the left caudate nucleus (Jacquemot \& Bachoud-Levi, in revision). This suggests that even if verbal and non-verbal executive control processes overlap in many cases, they can partially dissociate. Furthermore, Chan, Ryan, and Bever (2013) identified separate networks dedicated to verbal and nonverbal executive control and showed that the striatum is part of a language-specific executive control network. They contrasted verbal and non-verbal conditions in the same material in experiments assessing executive control and the expected responses were the same in the two conditions. The only difference was the rule governing reordering: in the verbal condition, material had to be re-ordered according to syntactic or lexico-semantic rules while in the non-verbal one it had to be re-ordered following switching rules order. The verbal condition showed higher activation of the left-lateralized frontal-subcortical network encompassing the anterior striatum (putamen and caudate nucleus), the dorsolateral and ventrolateral prefrontal cortex, and the supplementary motor area extending to the left anterior cingulate than the non-verbal condition (Chan et al., 2013).

These data trigger a conceptual move from a modular model of language including only linguistic units and rules toward an interactive model of the language system which includes executive control, working memory, and attentional resources. Ullman's proposal reflects a rather encapsulated approach of language (Fodor, 1983) whereas further models endorse an interactive view of language involving both working memory, executive, and attentional resources (Civier et al., 2013; Friederici, 2006; Mestres-Misse et al., 2012) while focusing on specific levels of language processing - phonetics, phonology, or syntax - all the while leaving apart the other levels of language. Here, we propose a model that integrates each step of language processing and the essential functions allowing for flaw less utilization.

In this model, the striatum is part of a verbal executive network that improves the efficiency and fluidity of language, enabling online processing of language at each level (phonetics, phonology, morphology, syntax, and lexico-semantics) by regulating, monitoring, and controlling the allocations of limited cognitive resources (verbal working memory and verbal attention) for processing linguistic units and rules (Fig. 3A). Its novelty is that rather than considering executive control, working memory, and attention as collaborating with language, we posit that they are part of the language system through their verbal component and that without them the language processes would not be efficient. Within the network linking the prefrontal cortex to the striatum, the left caudate would be required for the control of language processes, which refer to the allocation of resources for keeping track of verbal items selected and stored so far, to perform a linguistic task. The left putamen that shares both structural and functional connectivity with cortical areas involved in motor speech production may be more specifically related to the control of speech production to facilitate its motor execution (Fig. 2). In addition to this fronto-striatal loop, two networks provide an anatomical substrate of the language system that allows to reconcile data from different domains of cognition and pro- 

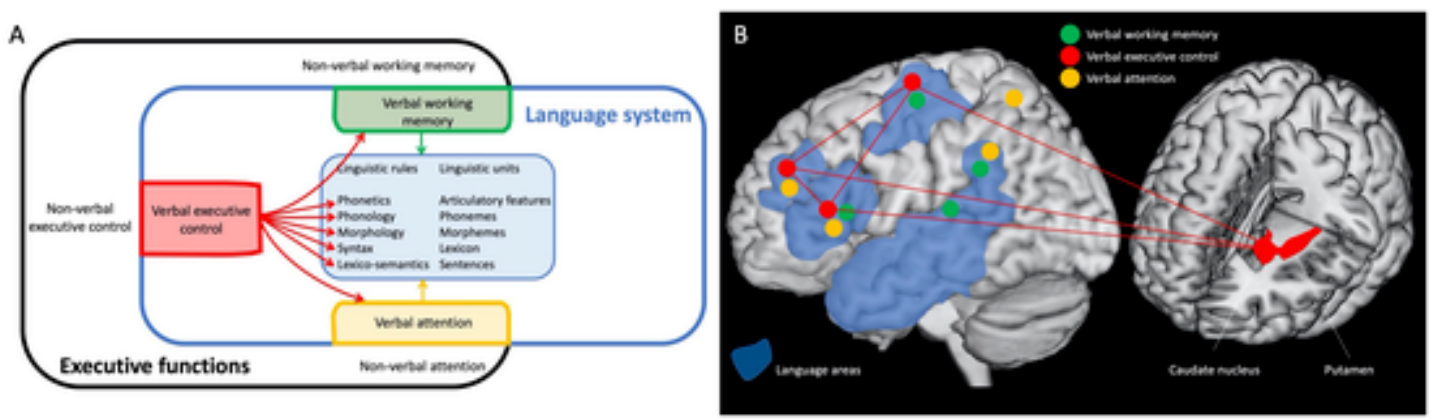

Fig. 3. Anatomico-functional integrative model of language. A. Functional model of language including executive control, working memory and attention resources. Executive functions include a non-verbal and a verbal component. The verbal components of executive control, working memory, and attention are part of the language system. The verbal executive control exerts control over the linguistic rules and units, the verbal working memory, and the verbal attention. B. Anatomical model of language system in the left hemisphere including verbal executive control associated with the dorsolateral and ventrolateral prefrontal cortex, and the supplementary motor area (Chan et al., 2013), verbal working memory associated with posterior superior temporal sulcus and supramarginal gyrus, the left ventrolateral prefrontal cortex, the supplementary motor area, and the insula (Jacquemot \& Scott, 2006; Lewis et al., 2004) and verbal attention associated with the left intraparietal sulcus, the temporo-parietal junction, the left inferior frontal gyrus, and middle frontal gyrus (Pugh et al., 1996; Shaywitz et al., 2001).

viding direction for future research: the ventrolateral prefrontal cortex, the supplementary motor area, the gyrus temporal superior, and the tempo-parietal junction are essential for the verbal working memory network, while the inferior parietal lobule, the dorsolateral and ventrolateral prefrontal cortex, and the tempo-parietal junction are central to verbal attention (Fig. 3B).

This might remind a proposition by Ben Shalom and Poeppel (Ben Shalom \& Poeppel, 2008; see also Hagoort, 2013) which describes the processing of language according to three types of operations: "memorizing" (retrieval of stored items) in the temporal lobe, "analyzing" (processing of items) in the parietal lobe, and "synthesizing" (combinatory process) in the frontal lobe. In our proposal, we aimed to clarify and specify the interaction betw een executive functions and each level of language processing. Although the underlying model is not equivalent, making direct comparison difficult, the "memorizing" function may correspond to the semantic memory and lexical-semantic units in our model. The "analyzing" function relates to working memory and at tention process that involve tw o separate networks in our model with mainly frontal and temporal regions for working memory and frontal and parietal regions for attention (Fig. 3B). The "synthetizing" function corresponds to the executive control of language processes, which we propose to be sustained by a network connecting the striatum to the frontal lobe (Figs. 2 and 3B). We also posit that the resources required for language to be efficient: executive control, working memory, and at tention contribute to the language system through a verbal component. Last but not least, in contrast with the cortical models, we integrate the striatum into our model, as an essential part of the language network connecting executive functions to language levels.

\section{Conclusion}

By proposing a review of the literature about the striatum's impact on language, it appears that reconciling all the data, imposes the formulation of an integrative model of language including not only the linguistic rules and units, but also their executive control by the striatum. This striatal role in executive control also applies to both verbal working memory and verbal attention as integrated components of language processing. Our proposal might appear over-simplified. However, it remains clear that most experiments designed for language exploration often treat executive functions as a whole. Conversely, studies exploring executive functions rarely specify the linguistic component at play, even if they imply language processing. This precludes providing a full specification of the model. In addition, some of the brain imaging experiments did not integrate networks but rather focused on regions of interests with an a priori focus on one domain or one structure, giving little place on the balance betw een several structures or domains of the same network, and thus to the striatum.

\section{Uncited references}

Friederici et al., 2003

Friederici et al., 2003

\section{Acknowledgments}

Our studies are supported by ANR-17-EURE-0017, ANR-11-INBS0011-05, ANR-11-JSH2-006-1, the Ministry of Health (national reference center for Huntington's disease) and the Fondation Maladies Rares (programme Sciences Humaines et Sociales \& Ma ladies Rares). We wish to think Karen Hernandez for the English editing and Renaud Massart and Marine Lunven for their valuable comments.

\section{References}

Abdullaev, Y. G., \& Melnichuk, K. V. (1997). Cognitive operations in the human caudate nucleus. Neuroscience Letters, 234(2-3), 151-155.

Abutalebi, J., Della Rosa, P. A., Gonzaga, A. K., Keim, R., Costa, A., \& Perani, D. (2013). The role of the left putamen in multilingual language production. Brain and Language, 125(3), 307-315. https://doi. org/10.1016/j. bandl.2012.03.009.

Abutal ebi, J., Miozzo, A., \& Cappa, S. F. (2000). Do subcortical structures control "language selection" in polyglots? Evidence from pathological language mixing. Neuroc ase, 6(1), 51-56.

Ali, N., Green, D. W., Kherif, F., Devlin, J. T., \& Price, C. J. (2010). The role of the left head of caudate in suppressing irrelevant words. Journal of Cognitive Neuroscience, 22(10), 2369-2386.

Amunts, K., \& Zilles, K. (2006). A multimodal analysis of structure and function in Broca's region. Broca's Region, 17-30.

Aron, A., Schlag hecken, F., Fletcher, P., Bullmore, E., Eimer, M., Barker, R., Robbins, T. (2003). Inhibition of subliminally primed responses is mediated by the caudate and thalamus: Evidence from functional MRI and Huntington's disease. Brain, 126(3), 713-723.

Astheimer, L. B., \& Sanders, L. D. (2009). Listeners modulate temporally selective attention during natural speech processing. Biological Psychology, 80(1), 23-34. https: //doi. or g/10.1016/j. biopsy cho. 2008.01.015.

Bachoud-Lévi, A.-C., \& Dupoux, E. (2003). An influence of syntactic and semantic variables on word form retrieval. Cognitive Neuropsychology, 20(2), 163-188. https: //doi. org/10.1080/02643290242000907.

Bechtereva, N. P., Abdullaev, Y. G., \& Medvedev, S. V. (1991). Neuronal activity in frontal speech area 44 of the human cerebral cortex during word recognition. Neuroscience Letters, 124(1), 61-64

Ben Shalom, D., \& Poeppel, D. (2008). Functional anatomic models of language: Assembling the pieces. The Neuroscientist, 14(1), 119-127.

Bialys tok, E., Craik, F. I., \& Luk, G. (2012). Bilingualism: Consequences for mind and brain. Trends in Cognitive Sciences, 16(4), 240-250.

Bialystok, E., \& Feng, X. (2009). Language proficiency and executive control in proactive interference: Evidence from monolingual and bilingual children and adults. Brain and Language, 109(2-3), 93-100.

Bohsal i, A., \& Crosson, B. (2016). The basal ganglia and language: A tale of two loops. 
The Basal Ganglia (pp. 217-242). Springer.

Bookheim er, S. (2002). Functional MRI of language: New approaches to understanding the cortical organization of semantic processing. Annual Review of Neuroscience, 25 (1), 151-188

Botvinick, M. M., Cohen, J. D., \& Carter, C. S. (2004). Conflict monitoring and anterior cingulate cortex: An update. Trends in Cognitive Sciences, 8(12), 539-546.

Broca, P. (1861). Perte de la parole, ramollissement chronique et destruction partielle du lobe antérieur gauche du cerveau. Bulletin de la So ciété Anthropologique, 2(1), 235-238.

Brunia, C., \& Van Boxtel, G. (2004). Anticipatory attention to verbal and non-verbal stimuli is reflected in a mo dality-specific SPN. Experimental Brain Research, 156(2), 231-239.

Cambier, J., Elghozi, D., \& Strube, E. (1979). Hémorragie de la tête du noyau caudé gauche. Revue Neurologique, 135(11), 714-763.

Caplan, D., \& Waters, G. S. (1999). Verbal working memory and sentence comprehension. Behavioral and Brain Sciences, 22, 77-126.

Cappa, S. F., Ca vallotti, G., Guidotti, M., Papagno, C., \& Vignolo, L. A. (1983). Subcortical aphasia: Two clinical-CT scan correlation studies. Cortex, 19(2), 227-241.

Ca ra ma zza, A. (1997). How many levels of processing are there in lexical access?. Cognitive Neuropsychology, 14(1), 177-208.

Catani, M., \& Thiebaut de Schotten, M. O. P. (2012). Atlas of human brain connections.

Chan, J., Stout, J., \& Vogel, A. (2019). Speech in prodromal and symptomatic Huntington's disease as a model of measuring onset and progression in dominantly inherited neurodegenerative diseases. Neuroscience \& Biobehavioral Reviews, 107, $450-460$.

Chan, S., Ryan, L., \& Bever, T. G. (2013). Role of the striatum in language: Syntactic and conceptual sequencing. Brain and Language, 125(3), 283-294.

Chatrchyan, S., Khachatryan, V., Sirunyan, A. M., Tuma sy an, A., Adam, W., Berg auer, T., ... Swanson, J. (2014). Measurement of the top-quark mass in alljets [formula: See text] events in pp collisions at [formula: See text] TeV. European Physical Journal C, 74(4), 2758. https://doi. org/10.1140/epjc/s1 0052-0142758-x.

Chomsky, N. (1965). Aspects of the theory of syntax. The MIT Press.

Civier, O., Bullock, D., Max, L., \& Guenther, F. H. (2013). Computational modeling of stuttering caused by impairments in a basal ganglia thalamo-cortical circuit involved in syllable selection and initiation. Brain and Language, 126(3), 263-278.

Cocchi, L., Zalesky, A., Fornito, A., \& Mattingley, J. B. (2013). Dynamic cooperation and competition between brain systems during cognitive control. Trends in Cognitive Sciences, 17(10), 493-501. https://doi. org/10.1016/j.tics.2013.08.006.

Colman, K. S., Ko erts, J., van Beilen, M., Leenders, K. L., Post, W. J., \& Bastia anse, R. (2009). The impact of executive functions on verb production in patients with Parkinson's disease. Cortex, 45(8), 930-942.

Couette, M., Bachoud-Levi, A. C., Brugieres, P., Si eroff, E., \& Bartolom eo, P. (2008). Orienting of spatial attention in Huntington's disease. Neuropsychologia, 46 (5), 1391-1400.

Cowan, N. (2010). The magical mystery four: How is working memory capacity limited, and why?. Current Directions in Psychological Science, 19(1), 51-57.

Crinion, J., Turner, R., Grogan, A., Hanakawa, T., Noppeney, U., Devlin, J. T., .. Price, C. J. (2006). Language control in the bilingual brain. Science, 312(5779), 1537-1540. https://doi. org/10.1126/science.1127761.

Crosson, B., McGregor, K., Gopinath, K. S., Conway, T. W., Benjam in, M., Chang, Y. L. , .. White, K. D. (2007). Functional MRI of language in aphasia: A review of the literature and the methodological challenges. Neuropsychology Review, 17(2), $157-177$.

Damasio, A. R., Damasio, H., Rizzo, M., Varney, N., \& Gersh, F. (1982). Aphasia with nonhemorrhagic lesions in the basal ganglia and internal capsule. Archives of Neurology, 39(1), 15-20.

Damasio, A. R., \& Tranel, D. (1993). Nouns and verbs are retrieved with differently distributed neural systems. Proceedings of the National Academy of Sciences, 90(11), 4957-4960.

De Diego-Balaguer, R., Couette, M., Dolbeau, G., Durr, A., Youssov, K., \& Bachoud-Levi, A. C. (2008). Striatal degeneration impairs language learning: Evidence from Huntington's disease. Brain, 131(Pt 11), 2870-2881. https://doi. org/10.1093/brain/awn242.

Deva uchelle, A.-D., Oppenheim, C., Rizzi, L., Dehaene, S., \& Pallier, C. (2009). Sentence syntax and content in the human temporal lobe: An fMRI adaptation study in auditory and visual mo dalities. Journal of Cognitive Neuroscience, 21(5), 1000-1012.

de Diego Balaguer, R., Costa, A., Sebastian-Galles, N., Juncadella, M., \& Ca ra ma zza, A. (2004). Regular and irregular morphology and its relation ship with agrammatism: Evidence from two Spanish-Catalan bilinguals. Brain and Language, 91(2), 212-222.

Diehl, S. K., Mefferd, A. S., Lin, Y.-C., Sellers, J., McDonell, K. E., de Riesthal, M. \& $\mathrm{Cl}$ aa ss en, D. O. (2019). Mo tor speech patterns in Huntington disease. Neurology, 93(22), e2042-e2052.

Drag anski, B., Kherif, F., Klöppel, S., Cook, P. A., Alexander, D. C., Parker, G. J., Frackowiak, R. S. (2008). Evidence for segregated and integrative connectivity patterns in the human basal ganglia. Journal of Neuroscience, 28(28), 7143-7152.

Duñabeitia, J. A., Hernández, J. A., Antón, E., Macizo, P., Estévez, A., Fuentes, L. J., \& Carreiras, M. (2014). The inhibitory advantage in bilingual children revisited. Experimental Psychology.

Fa roqi-Shah, Y. (2007). Are regular and irregular verbs dissociated in non-fluent aphasia?: A meta-analysis. Brain Research Bulletin, 74(1-3), 1-13.

Fedorenko, E. (2014). The role of domain-general cognitive control in language comprehension. Frontiers in Psychology, 5, 335. https://doi. org/10.3389/fpsyg. 2014.00335

Fiebach, C. J., Schlesewsky, M., Lohmann, G., Von Cram on, D. Y., \& Friederici, A. D. (2005). Revisiting the role of Broca's area in sentence processing: Syntactic integration versus syntactic working memory. Human Brain Mapping, 24(2), 79-91.

Filippi, R., Ceccolini, A., Periche-Tomas, E., Papageorgiou, A., \& Bright, P. (2020). Developmental trajectories of control of verbal and non-verbal interference in speech comprehension in monolingual and multilingual children. Cognition, 200, 104252.

Filippi, R., Leech, R., Thom as, M. S., Green, D. W., \& Dick, F. (2012). A bilingual advantage in controlling language interference during sentence comprehension. Bilingualism: Language and Cognition.

Filippi, R., Morris, J., Richardson, F. M., Bright, P., Thom as, M. S., KarmiloffSmith, A., \& Marian, V. (2015). Bilingual children show an advantage in controlling verbal interference during spoken language comprehension. Bilingualism (Cambridge, England), 18(3), 490.

Fodor, J. A. (1983). The modularity of mind. MA: MIT Press.

Friederici, A., Kotz, S., Werheid, K., Hein, G., \& von Cram on, D. (2003). Syntactic comprehension in Parkinson's disease: Investigating early automatic and late integrational processes using event-related brain potentials. Neuropsychology, 17(1), 133.

Friederici, A., Von Cram on, D., \& Kotz, S. (1999). Language related brain potentials in patients with cortical and subcortical left hemisphere lesions. Brain, 122(6), 1033-1047.

Friederici, A. D. (2002). Towards a neural basis of auditory sentence processing. Trends in Cognitive Sciences, 6(2), 78-84.

Friederici, A. D. (2006). What's in control of language?. Nature Neuroscience, 9(8), 991-992.

Friederici, A. D. (2011). The brain basis of language processing: From structure to function. Physiological Reviews, 91(4), 1357-1392.

Friederici, A. D., \& Kotz, S. (2003). The brain basis of syntactic processes: Functional imaging and lesion studies. Neuroimage, 20(Suppl. 1), S8-17.

Friederici, A. D., Rüschemeyer, S., Ha hne, A., \& Fiebach, C. (2003). The role of left inferior frontal and superior temporal cortex in sentence comprehension: Localizing syntactic and semantic processes. Cerebral Cortex, 13(2), 170-177.

Friederici, A. D., \& Singer, W. (2015). Grounding language processing on basic neurophysiological principles. Trends in Cognitive Sciences, 19(6), 329-338.

Geschwind, N. (1967). The varieties of naming errors. Cortex, 3(1), 97-112.

Giav azzi, M., Daland, R., Peperk am p, S., Palm interi, S., Brugières, P., Jacquemot, C., ... Bachoud-Levi, A. C. (2018). The role of the striatum in linguistic selection: Evidence from Huntington's disease and computational modeling. Cortex, 109, 189-204. https://doi.org/10.1016/j. cortex.2018.08.031.

Gira ud, A.-L., Neumann, K., Bachoud-Levi, A.-C., von Gudenberg, A. W., Euler, H. A., Lanfermann, H., \& Preibisch, C. (2008). Severity of dysfluency correlates with basal ganglia activity in persistent developmental stuttering. Brain and Language, 104 (2), 190-199. https://doi. org/10.1016/j. bandl.2007.04.005.

Gord on, W. P., \& Illes, J. (1987). Neurolinguistic characteristics of language production in Huntington's disease: A preliminary report. Brain and Language, 31(1), 1-10.

Grahn, J. A., Parkinson, J. A., \& Owen, A. M. (2008). The cognitive functions of the caudate nucleus. Progress in Neurobiology, 86(3), 141-155. https://doi. or g/10. 1016/j. pneurobio. 2008.09.004.

Grönholm, E., Roll, M., Horne, M., Sundgren, P., \& Lindgren, A. (2016). Predominance of caudate nucleus lesions in acute ischaemic stroke patients with impairment in language and speech. European Journal of Neurology, 23(1), $148-153$.

Grossm an, M., Lee, C., Morr is, J., Stern, M. B., \& Hurtig, H. I. (2002). Assessing resource demands during sentence processing in Parkinson's disease. Brain and Language, 80(3), 603-616. https://doi. org/10.1006/brln.2001.2630.

Grossman, M., Carvell, S., Stern, M. B., Gollomp, S., \& Hurtig, H. I. (1992). Sentence comprehension in Parkinson's disease: The role of attention and memory. Brain and Language, 42(4), 347-384.

Guenther, F. H., Ghosh, S. S., \& Tourville, J. A. (2006). Neural modeling and imaging of the cortical interactions underlying syllable production. Brain and Language, 96 (3), 280-301.

Guenther, F. H., \& Hickok, G. (2016). Neural models of motor speech control. Neurobiology of language (pp. 725-740). Elsevier.

Ha go ort, P. (2005). On Broca, brain, and binding: A new framework. Trends in Cognitive Sciences, 9(9), 416-423.

Hagoort, P. (2013). MUC (memory, unification, control) and beyond. Frontiers in Psychology, 4, 416

Heim er, L., Switzer, R. D., \& Van Hoesen, G. W. (1982). Ventral striatum and ventral pallidum: Components of the motor system?. Trends in Neurosciences, 5, 83-87.

Hervais-Adelma n, A., Moser-Mercer, B., Michel, C. M., \& Golestani, N. (2015). FMRI of simultaneous interpretation reveals the neural basis of extreme language control. Cerebral Cortex, 25(12), 4727-4739. https://doi. or g/10.1093/cercor/ bhu158.

Hi ckok, G., \& Poeppel, D. (2004). Dorsal and ventral streams: A framework for understanding aspects of the functional an atomy of language. Co gnition, 92(1-2), 67-99.

Hinzen, W., Ross ello, J., Morey, C., Cama ra, E., Garcia-Gorro, C., Salvador, R., \& de Diego-Balaguer, R. (2018). A systematic linguistic profile of spontaneous narrative speech in pre-symptomatic and early stage Huntington's disease. Cortex, 100, 71-83. https://doi. or g/10.1016/j. cortex.2017.07.022.

Hoffma n, P., Binney, R. J., \& Lambon Ralph, M. A. (2015). Differing contributions of inferior prefrontal and anterior temporal cortex to concrete and abstract conceptual knowledge. Cortex, 63, 250-266. https://doi. org/10.1016/j. cortex.2014.09. 001. 
Im-Bolter, N., Johnson, J., \& Pascual-Leone, J. (2006). Processing limitations in children with specific language impairment: The role of executive function. Child Development, 77(6), 1822-1841.

Indefrey, P., \& Levelt, W. J. (2004). The spatial and temporal signatures of word production components. Cognition, 92(1-2), 101-144.

Jacquemot, C., \& Bachoud-Levi, A. -C. (2021). A case-study of language-specific executive disorder. (In revision).

Jacquemot, C., Dupoux, E., \& Bachoud-Levi, A. C. (2011). Is the word-length effect linked to subvocal rehearsal?. Cortex, 47(4), 484-493. https://doi.org/10.1016/j. cortex.2010.07.007.

Jacquemot, C., Dupoux, E., Decouche, O., \& Bachoud-Levi, A.-C. (2006). Misperception in sentences but not in words: Speech perception and the phonological buffer. Cognitive Neuropsychology, 23(is sue 6), 949-971. Psychology Press https: //doi. org/10.1080/02643290600625749.

Jacquemot, C., Pallier, C., LeBihan, D., Dehaene, S., \& Dupoux, E. (2003). Phonological grammar shapes the auditory cortex: A functional magnetic resonance imaging study. The Journal of Neuroscience, 23(29), 9541-9546.

Jacquemot, C., \& Scott, S. K. (2006). What is the relation ship between phonological short-term memory and speech processing?. Trends in Cognitive Sciences, 10(11), 480-486. https://doi. or g/10.1016/j. tics.2006.09.002.

Ka ss ubek, J., Juengling, F. D., Ki oschies, T., Henkel, K., Ka ritzky, J., Kram er, B., Landwehrmeyer, G. B. (2004). Topography of cerebral atrophy in early Huntington's disease: A voxel based morphometric MRI study. Journal of Neurology, Neurosurgery \& Psychiatry, 75(2), 213. https://doi. or g/10.1136/jnnp. 2002. 009019.

Kotz, S. A., Frisch, S., Von Cram on, D. Y., \& Friederici, A. D. (2003). Syntactic language processing: ERP lesion data on the role of the basal ganglia. Journal of the International Neuropsychological So ciety, 9(7), 1053-1060.

Kreisler, A., Godefroy, O., Delm aire, C., Debachy, B., Leclercq, M., Pruvo, J.-P., \& Leys, D. (2000). The anatomy of aphasia revisited. Neurology, 54(5), 1117-1123.

Krishnan, S., Watkins, K. E., \& Bishop, D. V. (2016). Neurobiological basis of language learning difficulties. Trends in Cognitive Sciences, 20(9), 701-714.

La ia cona, M., \& Ca ra ma zza, A. (2004). The noun/verb dissociation in language production: Varieties of causes. Cognitive Neuropsychology, 21(2-4), 103-123.

Lawrence, A. D., Hodges, J. R., Ross er, A. E., Kershaw, A., ffrench-Constant, C., Rubinsztein, D. C., ,.. Sahakian, B. J. (1998). Evidence for specific cognitive deficits in preclinical Huntington's disease. Brain, 121(Pt 7), 1329-1341.

Lawrence, M., \& Barclay, D., III (1998). Stuttering: A brief review. American Family Physician, 57(9), 2175.

Le Stanc, L., Lunven, M., Giavazzi, M., Sliwinski, A., Brugieres, P., Youssov, K. Jacquemot, C. (2020). Attentional compensation in neurodegenerative diseases: The model of premanifest Huntington's disease mutation carriers. MedRxiv. https: // doi. or g/10.1101/2020.06.03.20121079. 2020.06.03.20121079.

Leh, S. E., Ptito, A., Chakravarty, M. M., \& Stra fella, A. P. (2007). Fronto-striatal connections in the human brain: A probabilistic diffusion tractography study. Neuroscience Letters, 419(2), 113-118.

Lehéricy, S., Ducros, M., Van De Moortele, P., Francois, C., Thivard, L., Poupon, C., ... Kim, D. (2004). Diffusion tensor fiber tracking shows distinct corticostriatal circuits in humans. Annals of Neurology, 55(4), 522-529.

Lehtonen, M., Soveri, A., La ine, A., Järv enpää, J., De Bruin, A., \& Antfolk, J. (2018). Is bilingualism associated with enhanced executive functioning in adults? A meta-analytic review. Psychological Bulletin, 144(4), 394.

van der Lely, H. K. J. (2005). Domain-specific cognitive systems: Insight from grammatical-SLI. Trends in Cognitive Sciences, 9(2), 53-59. https://doi. or g/10. 1016/j. tics.2004.12.002.

Leminen, A., Smolka, E., Duñabeitia, J. A., \& Pliatsikas, C. (2019). Morphological processing in the brain: The good (inflection), the bad (derivation) and the ugly (compounding). Structure in Words: The Present and Future of Morphological Processing in a Multidisciplinary Perspective, 116, 4-44. https://doi.org/10.1016/j. cortex.2018.08.016.

Lewis, S. J., Dove, A., Robbins, T. W., Barker, R. A., \& Ow en, A. M. (2004). Striatal contributions to working memory: A functional magnetic resonance imaging study in humans. European Journal of Neuroscience, 19(3), 755-760.

Lichteim, L. (1885). On aphasia. Brain, 7, 433-484.

Li eberman, P., Ka ko, E., Friedman, J., Tajchman, G., Feldman, L. S., \& Jiminez, E. B. (1992). Speech production, syntax comprehension, and cognitive deficits in Parkinson's disease. Brain and Language, 43(2), 169-189.

Liljeholm, M., \& O'Doherty, J. P. (2012). Contributions of the striatum to learning, motivation, and performance: An associative account. Trends in Cognitive Sciences, 16(9), 467-475.

Longworth, C. E., Keenan, S. E., Barker, R. A., Marslen-Wilson, W. D., \& Tyler, L. K. (2005). The basal ganglia and rule-governed language use: Evidence from vascular and degenerative conditions. Brain, 128(Pt 3), 584-596.

Ludlow, C. L., Connor, N. P., \& Bassich, C. J. (1987). Speech timing in Parkinson's and Huntington's disease. Brain and Language, 32(2), 195-214.

Ma cDermot, K. D., Bonora, E., Sykes, N., Coupe, A.-M., Lai, C. S., Vernes, S. C. Monaco, A. P. (2005). Identification of FOXP2 truncation as a novel cause of developmental speech and language deficits. The American Journal of Human Genetics, 76(6), 1074-1080.

Macdonald, M. E., Ambrose, C. M., Duya o, M. P., Myers, R. H., Lin, C., Srinidhi, L., ... Harper, P. S. (1993). A novel gene containing a Trinucleotide repeat that is expanded and unstable on huntingtons-disease chromosomes. Cell, 72(6), 971-983.

Makuuchi, M., Grodzinsky, Y., Am unts, K., Santi, A., \& Friederici, A. D. (2013). Processing noncanonical sentences in Broca's region: Reflections of movement distance and type. Cerebral Cortex, 23(3), 694-702.

Martin, R., \& Romani, C. (1994). Verbal working memory and sentence comprehension: A multiple-components view. Neuropsychology, 8, 506-523.

McCarthy, R., \& Warrington, E. K. (1985). Category specificity in an agrammatic patient: The relative impairment of verb retrieval and comprehension. Neuropsychologia, 23(6), 709-727.

McNab, F., \& Klingberg, T. (2008). Prefrontal cortex and basal ganglia control access to working memory. Nature Neuroscience, 11(1), 103-107. https://doi. or g/10. $1038 / \mathrm{nn} 2024$.

McNeil, M. R., \& Pratt, S. R. (2001). Defining aphasia: So me theoretical and clinical implications of operating from a formal definition. Aphasiology, 15(10-11), 901-911. https://doi.org/10.1080/02687040143000276.

Mestres-Miss e, A., Turner, R., \& Friederici, A. D. (2012). An anterior-posterior gradient of cognitive control within the dorsomedial striatum. Neuroimage, 62 , $41-47$

Miceli, G., Silveri, M. C., Villa, G., \& Ca ramazza, A. (1984). On the basis for the agrammatic's difficulty in producing main verbs. Cortex, 20(2), 207-220.

Monchi, O., Petrides, M., Stra fella, A., Worsley, K., \& Doyon, J. (2006). Functional role of the basal ganglia in the planning and execution of actions. Annals of Neurology, 59(issue 2), 257-264. WILEY-LISS https://doi. org/10.1002/ana. 20742.

Moro, A., Tettam anti, M., Perani, D., Donati, C., Cappa, S. F., \& Fazio, F. (2001). Syntax and the brain: Disentangling grammar by selective anomalies. Neuroimage, 13(1), 110-118. https://doi. org/10.1006/nimg.2000.0668.

Murray, L. L. (2017). Design fluency subsequent to on set of aphasia: A distinct pattern of executive function difficulties?. Aphasiology, 31(7), 793-818.

Nadeau, S. E., \& Crosson, B. (1997). Subcortical aphasia. Brain and Language, 58(3), $355-402$.

Nemeth, D., Dye, C., Gardian, G., Londe, Z., Klivenyi, P., Sefcsik, T., ... Ullm an, M. T. (2008). Function al morphology in pre-symptomatic huntington's disease: Evidence from Hungarian. In M. \& S. Grosvald D (Ed.). Proceedings of the Thirtyeighth western conference on linguistics (Vol. 19, pp. 241-251). Davis: Department of linguistics, University of California.

Nemeth, D., Dye, C. D., Sefcsik, T., Janacsek, K., Turi, Z., Londe, Z., ... others (2012). Language deficits in pre-symptomatic Huntington's disease: Evidence from Hungarian. Brain and Language, 121(3), 248-253.

Niendam, T. A., Laird, A. R., Ray, K. L., Dean, Y. M., Glahn, D. C., \& Carter, C. S. (2012). Meta-analytic evidence for a superordinate cognitive control network subserving diverse executive functions. Co gnitive, Affective, \& Behavioral Neuroscience, 12(2), 241-268. https://doi. or g/10.3758/s13415-011-0083-5.

Nota, Y., \& Honda, K. (2004). Brain regions involved in motor control of speech. Acoustical Science and Technology, 25(4), 286-289.

Novotný, M., Rusz, J., Čm ejla, R., Rưžičková, H., Klempíř, J., \& Růžička, E. (2016). Hypernasality associated with basal ganglia dysfunction: Evidence from Parkinson's disease and Huntington's disease. PeerJ, 4, e2530.

Paap, K. R., \& Greenberg, Z. I. (2013). There is no coherent evidence for a bilingual advantage in executive processing. Cognitive Psychology, 66(2), 232-258.

Paap, K. R., Johnson, H. A., \& Sawi, O. (2014). Are bilingual advantages dependent upon specific tasks or specific bilingual experiences?. Journal of Cognitive Psychology, 26(6), 615-639.

Pallier, C., Deva uchelle, A.-D., \& Dehaene, S. (2011). Cortical representation of the constituent structure of sentences. Proceedings of the National Academy of Sciences, 108(6), 2522-2527.

Pattam adilok, C., Dehaene, S., \& Pallier, C. (2016). A role for left inferior frontal and posterior superior temporal cortex in extracting a syntactic tree from a sentence. Cortex, 75, 44-55.

Patterson, K., Nestor, P. J., \& Rogers, T. T. (2007). Where do you know what you know? The representation of semantic knowledge in the human brain. Nature Review Neuroscience, 8(12), 976-987. https://doi. org/10.1038/nrn2277.

Penke, M., Janssen, U., \& Krause, M. (1999). The representation of inflectional morphology: Evidence from Broca's aphasia. Brain and Language, 68(1-2), $225-232$.

Péra n, P., Démonet, J.-F., Pernet, C., \& Cardebat, D. (2004). Verb and noun generation tasks in Huntington's disease. Movement Disorders: Official Journal of the Movement Disorder Society, 19(5), 565-571.

Pickett, E. R., Kuniholm, E., Protopapas, A., Friedman, J., \& Lieberma n, P. (1998). Selective speech motor, syntax and cognitive deficits associated with bilateral damage to the putamen and the head of the caudate nucleus: A case study. Neuropsychologia, 36(2), 173-188.

Pini, L., Jacquemot, C., Cagnin, A., Meneghello, F., Semenza, C., Mantini, D., \& Vallesi, A. (2020). Aberrant brain network connectivity in presymptomatic and manifest Huntington's disease: A systematic review. Human Brain Mapping, 41(1), 256-269.

Pini, L., Youssov, K., Sa mbataro, F., Bachoud-Levi, A.-C., Vall esi, A., \& Jacquemot, C. (2020). Striatal connectivity in pre-manifest Huntington's disease is differentially affected by disease burden. European Journal of Neurology, 27(11), 2147-2157.

Pinker, S., \& Prince, A. (1994). Regular and irregular morphology and the psychological status of rules of grammar. In R. L. C. S. D., Lima, \& G. K., Iverson (Eds.), The reality of linguistic rules. John Benjam ins.

Podoll, K., Caspary, P., Lange, H., \& Noth, J. (1988). Language functions in Huntington's disease. Brain, 111(6), 1475-1503.

Poeppel, D. (2014). The neuroa na to mic and neurophysiological infrastructure for speech and language. SI: Communication and Language, 28, 142-149. https://doi.org/ 10.1016/j. conb. 2014.07.005.

Price, C. J. (2012). A review and synthesis of the first 20 years of PET and fMRI studies of heard speech, spoken language and reading. Neuroimage, 62(2), 816-847. https://doi. org/10.1016/j. neuroima ge.2012.04.062. 
Pritchard, W. S., \& Hendrickson, R. (1985). The structure of human attention: Evidence for separate spatial and verbal resource pools. Bulletin of the Psychonomic So ciety, 23(3), 177-180. https://doi. or g/10.3758/BF03329819.

Provost, J.-S., Petrides, M., Si ma rd, F., \& Monchi, O. (2012). Investigating the longlasting residual effect of a set shift on fronto striatal activity. Cerebral Cortex, 22 (is sue 12), 2811-2819. Ox ford Univ Press Inc. https://doi. org/10.1093/cercor/ bhr358.

Pugh, K. R., Shay witz, B. A., Shay witz, S. E., Fulbright, R. K., Byrd, D., Skudlarski, P., ... others (1996). Auditory selective attention: An fMRI investigation. Neuroimage, 4(3), 159-173.

Pulvermuller, F., Huss, M., Kherif, F., Moscoso del Prado Martin, F., Ha uk, O., \& Shtyrov, Y. (2006). Motor cortex maps articulatory features of speech sounds. Proceedings of the National Academy of Sciences of the United States of America, 103(20), 7865-7870. https://doi. org/10.1073/pnas.0509989103.

Riad, R., Titeux, H., Lemo ine, L., Montillot, J., Bagnou, J. H., Ca o, X. N., Bachoud-Lévi, A.-C. (2020). Vocal markers from sustained phonation in Huntington's disease. ArXiv Preprint ArXiv, 2006, 05365.

Robles, S. G., Gatignol, P., Ca pelle, L., Mitchell, M.-C., \& Duffau, H. (2005). The role of dominant striatum in language: A study using intraoperative electrical stimulations. Journal of Neurology, Neurosurgery \& Psychiatry, 76(7), 940. https:// doi.org/10.1136/jnnp.2004.045948.

Rogers, R. D., Andrews, T., Gras by, P., Brooks, D., \& Robbins, T. (2000). Contrasting cortical and subcortical activations produced by attentional-set shifting and reversal learning in humans. Journal of Cognitive Neuroscience, 12(1), $142-162$.

Rusz, J., Saft, C., Schlegel, U., Hoffma n, R., \& Skodda, S. (2014). Phonatory dysfunction as a preclinical symptom of Huntington disease. PLoS One, 9(11), e113412. https://doi. or g/10.1371/journal. pone.0113412.

Sambin, S., Teichmann, M., Sportiche, D., Schlenker, P., \& Bachoud-Lévi, A. C. (2012). The role of the striatum in sentence processing: Disentangling syntax from working memory in Huntington's disease. Neuropsychologia, 50, 2625-2635.

Shao, Z., Roelofs, A., \& Meyer, A. S. (2012). Sources of individual differences in the speed of naming objects and actions: The contribution of executive control. Quarterly Journal of Experimental Psychology (2006), 65(10), 1927-1944. https://doi.org/ 10.1080/17470218.2012.670252.

Shapiro, K., \& Caramazza, A. (2003). Looming a loom: Evidence for independent access to grammatical and phonological properties in verb retrieval. Journal of Neurolinguistics, 16(2-3), 85-111.

Shapiro, K., Shelton, J., \& Ca ra mazza, A. (2000). Grammatical class in lexical production and morhpological processing: Evidence from a case of fluent aphasia. Cognitive Neuropsychology, 17(8), 665-682.

Shay witz, B. A., Shay witz, S. E., Pugh, K. R., Fulbright, R. K., Skudlarski, P., Mencl, W. E., ... Gore, J. C. (2001). The functional neural architecture of components of attention in language-processing tasks. NeuroImage, 13(4), 601-612. https://doi. org/10.1006/nimg.2000.0726.

Silveri, M. C., \& Di Betta, A. M. (1997). Noun-verb dissociations in brain-damaged patients: Further evidence. Neurocase, 3(6), 477-488.

Simonyan, K. , Hers covitch, P., \& Horwitz, B. (2013). Speech-induced striatal dopamine release is left lateralized and coupled to functional striatal circuits in healthy humans: A combined PET, fMRI and DTI study. Neuroimage, 70, 21-32. https://doi. org/10.1016/j. neuroima ge.2012.12.042.

Skodda, S., Grönheit, W., Lukas, C., Bellenberg, B., von Hein, S. M., Hoffma nn, R., \& Saft, C. (2016). Two different phenomena in basic motor speech performance in premanifest Huntington disease. Neurology, 86(14), 1329. https://doi.org/10. 1212/WNL. 0000000000002550.

Skodda, S., Grönheit, W., Schlegel, U., Südmeyer, M., Schnitzler, A., \& Wojtecki, L. (2014). Effect of subthalamic stimulation on voice and speech in Parkinson's disease: For the better or worse?. Frontiers in Neurology, 4, 218.

Snowden, J. S. (2017). The neuropsychology of Huntington's disease. Archives of Clinical Neuropsychology, 32(7), 876-887.

Tabrizi, S. J., Reilmann, R., Roos, R. A., Durr, A., Leavitt, B., Ow en, G., ... Lang behn, D. R. (2012). Potential endpoints for clinical trials in premanifest and early Huntington's disease in the TRACK-HD study: Analysis of 24 month observational data. Lancet Neurology, 11(1), 42-53. https://doi.org/10.1016/ S1 474-4422(11)70263-0.

Taler, V., Aaron, G. P., Steinmetz, L. G., \& Pisoni, D. B. (2010). Lexical neighborho od density effects on spok en word recognition and production in healthy aging. The Journals of Gerontology. Series B, Psychological Sciences and So cial Sciences, 65(5), 551-560.

Teichmann, M., Darcy, I., Bachoud-Levi, A. C., \& Dupoux, E. (2009). The role of the striatum in phonological processing: Evidence from early stages of Huntington's disease. Cortex, 45(7), 839-849.

Teichmann, M., Dupoux, E., Cesa ro, P., \& Bachoud-Levi, A. C. (2008). The role of the striatum in sentence processing: Evidence from a priming study in early stages of Huntington's disease. Neuropsychologia, 46(1), 174-185.

Teichmann, M., Dupoux, E., Kouider, S., \& Bachoud-Lévi, A. C. (2006). The role of the striatum in processing language rules: Evidence from word perception in Huntington's disease. Journal of Cognitive Neuroscience, 18(9), 1555-1569.

Teichmann, M., Dupoux, E., Kouider, S., Brugieres, P., Bois sé, M.-F., Baudic, S., ,.. Bachoud-Lévi, A.-C. (2005). The role of the striatum in rule application: The model of Huntington's disease at early stage. Brain: A Journal of Neurology, 128, 1155-1167. https://doi. org/10.1093/brain/awh472.

Teichmann, M., Gaura, V., Demonet, J. F., Supiot, F., Delliaux, M., Verny, C., . Bachoud-Levi, A. C. (2008). Language processing within the striatum: Evidence from a PET correlation study in Huntington's disease. Brain, 131(Pt 4), 1046-1056.

Teichmann, M., Rosso, C., Martini, J., Bloch, I., Brugières, P., Duffau, H., Bachoud-Lévi, A. (2015). A cortical-subcortical syntax pathway linking B roca's area and the striatum. Human Brain Mapping, 36(6), 2270-2283.

Tettam anti, M., Moro, A., Messa, C., Moresco, R. M., Rizzo, G., Carpinelli, A., ... Pera ni, D. (2005). Basal ganglia and language: Phonology modulates dopaminergic release. Neuroreport, 16(4), 397-401. https://doi.org/10.1097/00001756200503150-00018.

Tomasi, D., \& Volkow, N. D. (2012). Resting functional connectivity of language networks: Characterization and reproducibility. Molecular Psychiatry, 17(8), 841-854.

Ullm an, M. T. (2001). The declarative/procedural model of lexicon and grammar. Journal of Psycholinguistic Research, 30(1), 37-69.

Ullm an, M. T., Cork in, S., Coppola, M., Hickok, G., Growdon, J. H., Koro shetz, W. J., \& Pinker, S. (1997). A neural dissociation within language: Evidence that the mental dictionary is part of declarative memory, and that grammatical rules are processed by the procedural system. Journal of Cognitive Neuroscience, 9(2), 266-276. https://doi.org/10.1162/jocn.1997.9.2.266.

Vandenberg he, R., Price, C., Wise, R., Josephs, O., \& Frackowiak, R. S. (1996). Functional anatomy of a common semantic system for words and pictures. Nature, 383(6597), 254-256.

Vogel, A. P., Shirbin, C., Churchyard, A. J., \& Stout, J. C. (2012). Speech acoustic markers of early stage and prodromal Huntington's disease: A marker of disease on set?. Neuropsychologia, 50(14), 3273-3278. https://doi. or g/10.1016/j. neuropsy cholog ia.2012.09.011.

Vonsattel, J. P., Myers, R. H., Stevens, T. J., Ferrante, R. J., Bird, E. D., \& Richardson, E. P. (1985). Neuropathological classification of Huntington's disease. Journal of Neuropathology and Experimental Neurology, 44, 559-577.

Watkins, K. E., Dronkers, N. F., \& Vargha-Khadem, F. (2002). Behavioural analysis of an inherited speech and language disorder: Comparison with acquired aphasia. Brain, 125(3), 452-464.

Watkins, K. E., Vargha-Khadem, F., Ashburner, J., Passingham, R. E., Connelly, A., Friston, K. J., ... Gadian, D. G. (2002). MRI analysis of an inherited speech and language disorder: Structural brain abnormalities. Brain, 125(3), 465-478.

Wernicke, C. (1874). Der aphasische Symptomencomplex: Eine psychologische Studie auf anatomischer basis. Cohn \& Weig ert.

Wolf, R. C., Vasic, N., Schönfeldt-Lecuona, C., Ecker, D., \& Landwehrmeyer, G. B. (2009). Cortical dysfunction in patients with Huntington's disease during working memory performance. Human Brain Mapping, 30(1), 327-339. 